\title{
Synthesizing High-Resolution Climatological Wind Fields with a Mesoscale Atmospheric Boundary Layer Model Forced with Local Weather Observations
}

\author{
Guillermo J. Berri \\ National Meteorological Service, Buenos Aires \\ Argentina
}

\section{Introduction}

The region of the La Plata River in southeastern South America (see Fig. 1) concentrates important economic and social activities since one third of the population of Argentina and more than one half the population of Uruguay live there. Large urban complexes, different commercial activities and important industries are located along its shores. In addition, the La Plata River and its tributary the Paraná River are main ship tracks with some of the largest ports of the southern cone of South America. Therefore, the region is of vital importance for the two countries. The La Plata River is a large water surface that projects into the continent, conditioning the local weather and climate. Thus, other related environmental aspects are strongly influenced by the local weather and climate conditions, such as environmental pollution, water currents and tidal regime, commercial fishing at the oceanic front, port operations, navigation and tourism.

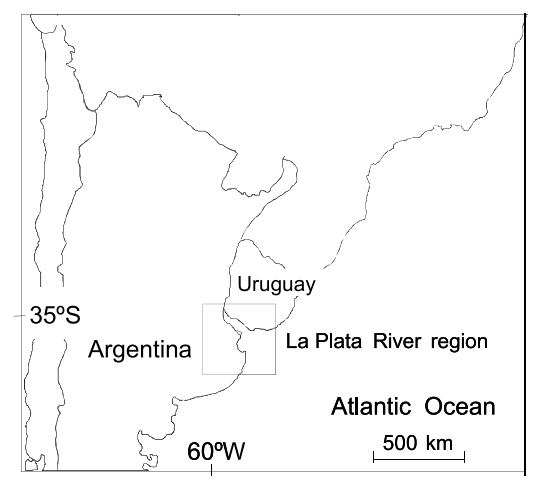

Fig. 1. Location of La Plata River region in South America

The La Plata River is $300 \mathrm{~km}$ long, with a variable width between $40 \mathrm{~km}$ and $200 \mathrm{~km}$. The region creates a considerable surface temperature contrast with the continent that sets up the stage for the development of a low-level circulation, with sea-land breeze characteristics. 
During the daytime hours the lower layers over land are warmer than over the river, creating a land-river surface temperature gradient that establishes a river to land wind component known as sea breeze. Over the northern shore of the La Plata River the surface winds increase the southerly component, while over the southern shore they increase the northerly wind component.

The daytime inland surface wind components create horizontal divergence and subsidence over the river and convergence and upward motion over land near the river shores. During the nighttime hours the land is cooler than the river, the land-river surface temperature gradient reverses and the winds tend to blow from land to river establishing the land breeze. The nighttime land breeze is not so well developed as the daytime sea breeze basically because of weaker low level winds due to the nocturnal stability. The daily cycle of the land-river surface temperature contrast gives rise to significant changes of the predominant wind direction across the region throughout the day. This can be appreciated in Fig. 2 that shows the observed 1959-1984 mean winds at five weather stations in the

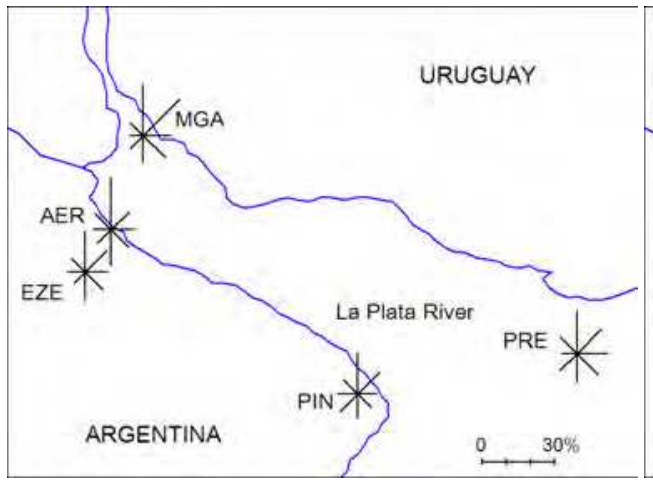

a) 0900 LST

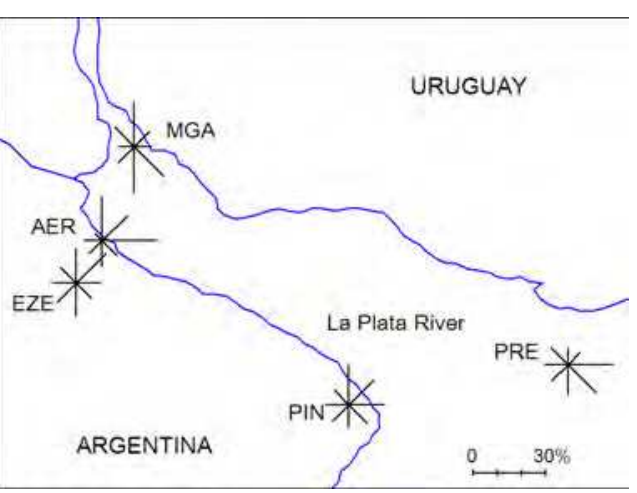

b) 1500 LST

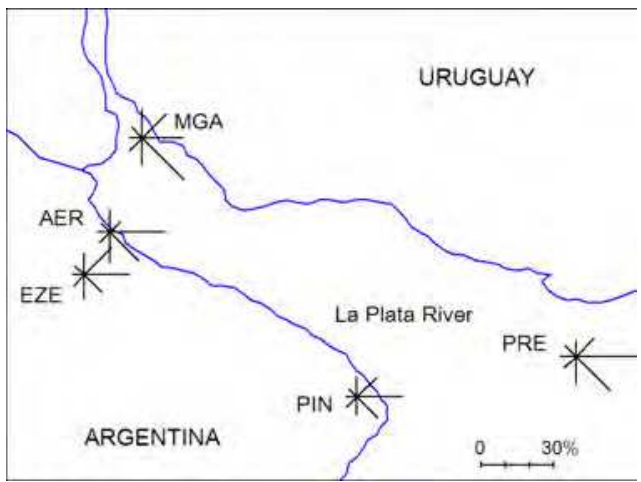

c) 2100 LST

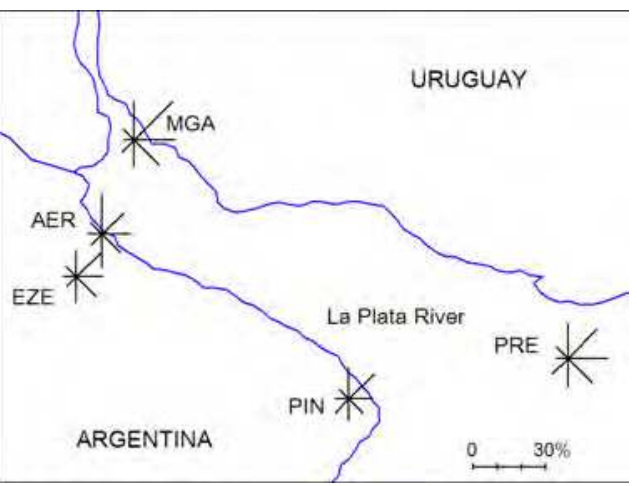

d) 0300 LST

Fig. 2. Observed 1959-1984 mean wind direction frequencies (in percentage) at four local standard times (LST): a) 0900 LST, b) 1500 LST, c) 2100 LST and d) 0300 LST. The weather stations are Ezeiza (EZE), Aeroparque (AER), Martín García (MGA), Punta Indio (PIN) and Pontón Recalada (PRE). 
region. The weather stations used in the study are Ezeiza (EZE), Aeroparque (AER), Martín García (MGA), Punta Indio (PIN) and Pontón Recalada (PRE). At 0900 LST (local standard time) (Fig. 2a), all weather stations show predominant $\mathrm{N}$ and NE wind sectors that together amount between $30 \%-40 \%$ of the time. At 1500 LST (Fig. 2b) the weather stations over land in Argentina display the N, NE and E wind sectors as the dominant ones, totalizing $40 \%$ $60 \%$ of the time (in particular AER has an E wind frequency of $23 \%$ ). In contrast, the weather stations over the river display as dominant sectors the E, SE and S wind directions.

At 2100 LST (Fig. 2c) the dominant wind sector over land is E, followed by SE, as well as over PRE at the river mouth, whereas over MGA is SE followed by E. The wind direction frequency distribution at 0300 LST (Fig. 2d) looks quite similar to that of 0900 LST. Table 1 shows the mean wind speed by wind sector at the four different times of the day. Throughout the day the weather stations over the river display a significant change of the dominant wind sectors of more than one quadrant $\left(90^{\circ}\right.$ to $\left.130^{\circ}\right)$, while in the stations over land the daily change is less than one quadrant.

Atmospheric mesoscale models have the capability of reproducing the major aspects of the sea-land breeze circulation when the horizontal thermal contrast is properly defined. In some regions where the sea breeze circulation is important, it is common to adapt existent numerical models to study this local circulation. For example Pielke et al. (1992) describe the use of the RAMS model in sea-land breeze studies, employing telescopic and nested grids; Case et al. (2002) use the RAMS model coupled to the Eta model to simulate the sea breeze over the eastern coast of the Florida peninsula, and Colby (2004) employs the MM5 model with different resolutions in the study of the sea breeze over the New England coast. Seabreeze cases over northwestern Hawaii were simulated using the NCEP (National Centers for Environmental Prediction) mesoscale spectral model coupled with an advanced land surface model with $3 \mathrm{~km}$ horizontal resolution (Zhang, 2005). The inland penetration of the lake breeze on the western shore of Lake Michigan was studied by Roebber \& Gehring (2000) using the MM5 mesoscale model with $5 \mathrm{~km}$ grid spacing. Some boundary layer forecast models have been developed to study the breeze in complex terrains, for example Daggupaty (2001) that simulates the 3-dimensional circulation associated with lake breezes in southwestern Ontario. One of the main problems with regional models is the resolution required to represent the short to mid-term regional-scale processes, as discussed by Colby (2004). An important aspect in modelling local scale circulations is the verification of predictions, as done for example by Case (2004) over east central Florida.

Berri \& Nuñez (1993) show that the sea-land breeze circulation over the La Plata River region can be simulated with a mesoscale boundary layer model (BLM) especially developed for the region. The results obtained by the authors in a case study show good agreement between observed and modeled surface wind direction changes throughout the day. The daily cycle of the sea-land breeze responds to the atmospheric pressure anomaly field induced by the cyclic thermal contrast at the surface. Thus, the driving mechanism of the abovementioned model is the daily variation of the horizontal temperature difference across the river shores.

A recent study (Sraibman \& Berri 2009) finds that operational low level wind forecast for the La Plata River region can be improved by running the BLM model forced by the Eta model operational forecasts. This study concludes that the improvement obtained with the BLM model is a consequence of the appropriate definition of the land-river surface 
temperature contrast that is fundamental for resolving the small scale details of the lowlevel circulation over the region.

\begin{tabular}{|lcccccccc|}
\hline 0300 LST & $\mathrm{N}$ & $\mathrm{NE}$ & $\mathrm{E}$ & $\mathrm{SE}$ & $\mathrm{S}$ & $\mathrm{SW}$ & $\mathrm{W}$ & $\mathrm{NW}$ \\
EZE & 3.8 & 3.5 & 2.9 & 3.7 & 4.0 & 3.5 & 3.2 & 3.2 \\
AER & 5.2 & 5.2 & 3.9 & 5.1 & 5.7 & 4.7 & 4.2 & 4.3 \\
MGA & 4.1 & 4.6 & 4.5 & 5.3 & 6.1 & 4.8 & 4.3 & 4.3 \\
PIN & 4.6 & 4.6 & 4.7 & 4.8 & 5.0 & 4.6 & 3.9 & 4.4 \\
PRE & 6.4 & 7.0 & 6.5 & 7.1 & 8.3 & 9.0 & 6.8 & 6.1 \\
\hline 0900 LST & $\mathrm{N}$ & $\mathrm{NE}$ & $\mathrm{E}$ & $\mathrm{SE}$ & $\mathrm{S}$ & $\mathrm{SW}$ & $\mathrm{W}$ & $\mathrm{NW}$ \\
EZE & 4.1 & 4.2 & 3.7 & 4.4 & 4.7 & 4.1 & 3.6 & 3.7 \\
AER & 4.7 & 4.4 & 3.7 & 5.3 & 5.7 & 5.1 & 4.8 & 4.4 \\
MGA & 4.4 & 4.9 & 4.7 & 5.8 & 6.1 & 4.8 & 4.2 & 4.3 \\
PIN & 5.1 & 5.0 & 5.3 & 5.5 & 5.1 & 4.8 & 4.4 & 5.0 \\
PRE & 6.4 & 6.0 & 5.6 & 7.5 & 7.6 & 7.8 & 7.1 & 6.2 \\
\hline 1500 LST & $\mathrm{N}$ & $\mathrm{NE}$ & $\mathrm{E}$ & $\mathrm{SE}$ & $\mathrm{S}$ & $\mathrm{SW}$ & $\mathrm{W}$ & $\mathrm{NW}$ \\
EZE & 4.7 & 4.6 & 4.7 & 5.0 & 5.3 & 5.4 & 5.0 & 4.6 \\
AER & 3.9 & 2.9 & 3.5 & 5.3 & 6.6 & 6.7 & 6.6 & 5.7 \\
MGA & 3.7 & 3.9 & 4.2 & 4.7 & 4.2 & 4.4 & 4.3 & 3.5 \\
PIN & 5.4 & 4.5 & 5.6 & 6.0 & 6.0 & 5.9 & 5.7 & 6.2 \\
PRE & 3.9 & 4.8 & 5.5 & 6.4 & 6.7 & 7.0 & 5.8 & 5.4 \\
\hline 2100 LST & $\mathrm{N}$ & $\mathrm{NE}$ & $\mathrm{E}$ & $\mathrm{SE}$ & $\mathrm{S}$ & $\mathrm{SW}$ & $\mathrm{W}$ & $\mathrm{NW}$ \\
EZE & 3.1 & 2.9 & 3.6 & 4.5 & 4.1 & 3.5 & 3.1 & 2.8 \\
AER & 3.8 & 3.2 & 4.1 & 5.4 & 5.9 & 5.1 & 4.1 & 3.6 \\
MGA & 3.5 & 4.3 & 4.5 & 5.6 & 5.9 & 5.2 & 4.2 & 3.6 \\
PIN & 3.7 & 4.1 & 4.8 & 4.9 & 5.3 & 4.5 & 3.7 & 3.8 \\
PRE & 4.4 & 5.3 & 6.8 & 7.5 & 7.7 & 8.3 & 6.3 & 5.1 \\
\hline
\end{tabular}

Table 1. Mean wind speed by wind sector $\left(\mathrm{m} \mathrm{s}^{-1}\right)$, at the four main observing times of the day, at the five weather stations of the study Ezeiza (EZE), Aeroparque (AER), Martín García (MGA), Punta Indio (PIN) and Pontón Recalada (PRE). The averaging period is 1959-1984.

\section{BLM model formulation}

The BLM is a hydrostatic and incompressible model that has been developed by Berri (1987). The model equations are based on the three principles that govern the atmospheric motion, i.e. conservation of momentum, mass and energy. Since the model is formulated for studying the atmospheric circulation in the boundary layer, the vertical component of the equation of motion becomes the hydrostatic equation and the mass conservation principle is approximated by the continuity equation for an incompressible fluid. Since the model is dry, all energy sources have been neglected, except the surface heating, so that the energy equation reduces to the conservation of potential temperature. The BLM model equations are: 


$$
\begin{gathered}
\frac{\partial u}{\partial t}=-u \frac{\partial u}{\partial x}-v \frac{\partial u}{\partial y}-w \frac{\partial u}{\partial z}-\alpha_{0} \frac{\partial p}{\partial x}+f v+\frac{\partial}{\partial x}\left(K_{m h} \frac{\partial u}{\partial x}\right)+\frac{\partial}{\partial y}\left(K_{m h} \frac{\partial u}{\partial y}\right)+\frac{\partial}{\partial z}\left(K_{m z} \frac{\partial u}{\partial z}\right) \\
\frac{\partial v}{\partial t}=-u \frac{\partial v}{\partial x}-v \frac{\partial v}{\partial y}-w \frac{\partial v}{\partial z}-\alpha_{0} \frac{\partial p}{\partial y}-f u+\frac{\partial}{\partial x}\left(K_{m h} \frac{\partial v}{\partial x}\right)+\frac{\partial}{\partial y}\left(K_{m h} \frac{\partial v}{\partial y}\right)+\frac{\partial}{\partial z}\left(K_{m z} \frac{\partial v}{\partial z}\right) \\
\frac{\partial \theta}{\partial t}=-u \frac{\partial \theta}{\partial x}-v \frac{\partial \theta}{\partial y}-w \frac{\partial \theta}{\partial z}+\frac{\partial}{\partial x}\left(K_{\theta h} \frac{\partial \theta}{\partial x}\right)+\frac{\partial}{\partial y}\left(K_{\theta h} \frac{\partial \theta}{\partial y}\right)+\frac{\partial}{\partial z}\left(K_{\theta z} \frac{\partial \theta}{\partial z}\right) \\
\frac{\partial w}{\partial z}=-\frac{\partial u}{\partial x}-\frac{\partial v}{\partial y} \\
\frac{\partial p_{0}}{\partial z}=-\frac{g}{\alpha_{0}} \\
\frac{\partial p^{\prime}}{\partial z}=\frac{g}{\alpha_{0}} \frac{\theta^{\prime}}{\theta_{0}} \\
p=p_{0}+p^{\prime} \\
\theta^{\prime}=\theta-\theta_{0}
\end{gathered}
$$

All symbols in the equations have the usual meteorological meaning, subscript $o$ refers to a horizontal mean value over the entire domain, and superscript 'refers to a local departure from the horizontal mean value. Equations (1) to (3) are the forecast equations for the $u$ and $v$ wind components and potential temperature $\theta$, respectively. Equations (4) to (8) are the diagnostic equations for the vertical motion $w$, standard pressure $p_{0}$, pressure perturbation $p^{\prime}$, total pressure $p$, and potential temperature perturbation $\theta^{\prime}$, respectively. Equations (1) to (3) are solved from the top of the surface layer $(z=40 \mathrm{~m})$ to the material top of the model by a semi-implicit numerical scheme. Within the constant flux layer, the similarity theory is applied and the forecast equations become the well-known diagnostic equations, i.e. the logarithmic vertical profiles of wind and potential temperature, as a function of stability. The boundary conditions at the top of the model are: $u=u_{g}, v=v_{g}, w=p^{\prime}=\theta^{\prime}=0$ where $u_{g}$ and $v_{g}$ are the geostrophic wind components. At the lower boundary the conditions are: $u=$ $v=w=0$, whereas $\theta$ is defined at every time step (see below Section 3.1). At the lateral boundaries, all variables are allowed to change in order to provide a zero gradient across the boundaries at each time step, except the pressure since its gradient provide the geostrophic wind. The model is initialized under conditions of horizontal homogeneity for all the variables except pressure, since its gradient supports the geostrophic wind at the initial state. Thus, Equations (1) and (2) become the well-known Ekman layer equations:

$$
\frac{\partial u}{\partial t}=f\left(v-v_{g}\right)+\frac{\partial}{\partial z}\left(K_{m z} \frac{\partial u}{\partial z}\right)
$$




$$
\frac{\partial v}{\partial t}=-f\left(u-u_{g}\right)+\frac{\partial}{\partial z}\left(K_{m z} \frac{\partial v}{\partial z}\right)
$$

in which the pressure force terms are replaced by the expressions of the geostrophic equilibrium with constant $u_{g}$ and $v_{g}$. Equation (5) is integrated once and Equations (9) and (10) are integrated during three inertial periods (about 60 hours at this latitude), in order to remove any possible inertial oscillations from the solution. Thus, the steady state solution achieved for $u$ and $v$ at every grid point of the domain depends only on the particular values adopted at the upper and lower boundaries. These are defined from the 0900 LST observations and are kept constant during the initialization process. For more details about the model formulation and the numerical method of solution, please refer to Berri \& Nuñez (1993).

The inner rectangle of Fig. 1 depicts the domain of the BLM forecasts that consists of 79 points in the $x$ direction $(350 \mathrm{~km})$ and 58 points in the $y$ direction $(316 \mathrm{~km})$. The horizontal resolution is $0.05^{\circ}$ that corresponds to an average of $5 \mathrm{~km}$. The vertical domain has 12 levels distributed according to a log-linear spacing. The first level is the roughness length $z_{0}$ (equal to $0.001 \mathrm{~m}$ over water and $0.01 \mathrm{~m}$ over land), and the last one is the material top of the model at $2000 \mathrm{~m}$. The intermediate levels are located at the following heights: 10, 40, 80, 140, 220, $350,550,800,1100$ and $1500 \mathrm{~m}$.

\section{Methodology for the model climatology}

The low-level wind field climatology of the model is defined as the ensemble result obtained by running a series of 18-hour forecasts. Each ensemble member is a forecast obtained by forcing the model with a different upper and lower boundary condition defined from the local observations. The upper boundary condition consists of a given value of wind direction and wind speed at the top of the model, defined from the Ezeiza radiosonde observations (EZE in Fig. 2). The lower boundary condition consists of a surface heating function (see below Section 3.1), defined from the temperature observations at the surface weather stations in the region. The ensemble result is obtained by averaging the wind direction and wind speed of all the ensemble members. The data corresponds to 1959-1984, the only extended period with complete observations available in a suitable manner for the study. The model results are validated at 0300, 0900, 1500 and 2100 LST, which are the times of the day when the observations are available in the historical database. Since the model is initialized at 0900 LST, the 18-hour forecast runs until 0300 LST of the following day that is the last time of validation.

\subsection{Boundary conditions}

The model ensemble consists of 192 members, each one characterized by a wind direction and a wind speed at the top of the model. The 192 members correspond to 16 wind direction classes (N, NNE, NE,.., NNW), and 12 wind speed classes with the following upper bounds in ms $^{-1}: 2,3,4,5,6,7,8,9,10,12,14$, with the last class representing wind speeds greater than $14 \mathrm{~ms}^{-1}$. Each ensemble member has a probability of occurrence $p_{j} \quad(j=1$ to 192), that is determined from the mean wind frequency distribution of the 0900 LST Ezeiza radiosonde data of the period 1959-1984. 
For each ensemble member, the surface heating function defines the temperature at the surface as follows: $T(x, y, t)=T_{o}+F_{1}(t) F_{2}(x, y)$, where $T_{o}$ is the daily mean temperature of the ensemble, $F_{1}(t)$ defines the daily cycle of the maximum river-land temperature difference, and $F_{2}(x, y)$ defines the river-land temperature difference as a function of the distance between every $(x, y)$ point and the coast. Except nearby the coasts, the horizontal air temperature gradients over the land and over the river are much smaller than the river-land air temperature gradient. Thus, the main forcing that drives the model at the surface is the daily variation of the horizontal air temperature difference across the coasts. Two weather stations are chosen for determining this forcing, one in the land -Ezeiza (EZE)- and the other one in the river -Pontón Recalada (PRE)-. The temperature difference $T_{E Z E}-T_{P R E}$ is calculated from the four daily observations at 0300, 0900, 1500 and 2100 LST. Then, the mean value is obtained as the average of all days in which the Ezeiza radiosonde observation corresponds to every wind direction and wind speed class at the top of the model. Thus, for each ensemble member there are four daily temperature differences, which are interpolated by means of a harmonic analysis in order to obtain $F_{1}(t)$. Fig. 3 depicts typical $F_{1}(t)=T_{E Z E}-$ $T_{P R E}$ curves, as monthly mean values for four different months of the year. The land-river temperature difference is defined as follows: $F_{2}(x, y)=\{1+\tanh [s(x, y) / B]\} / 2$, where $s(x, y)$ is the minimum distance from every grid point to the coast (positive over the land and negative over the river).

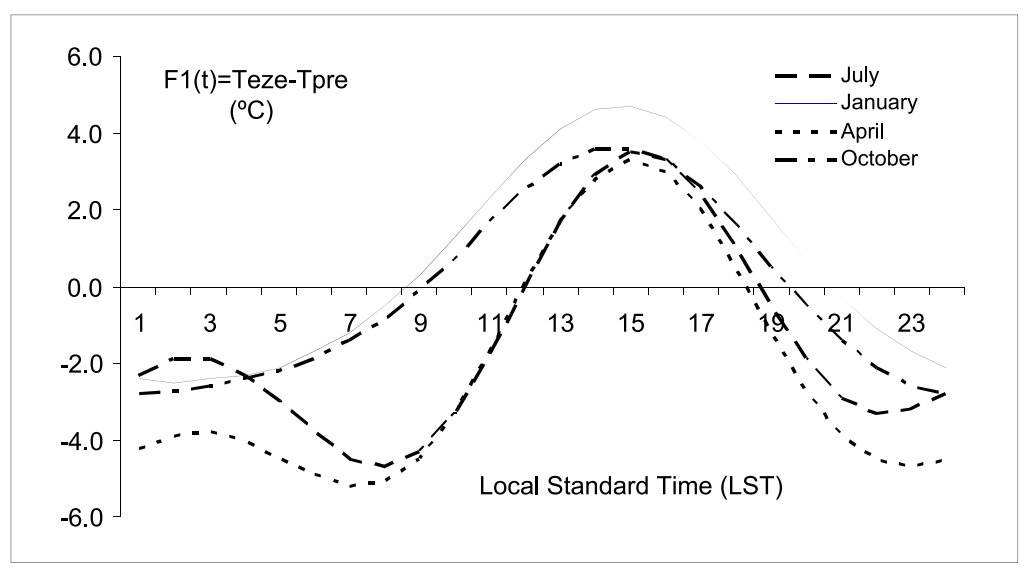

Fig. 3. Typical hourly interpolated $F_{1}(t)$ curves, in ${ }^{\circ} \mathrm{C}$, from the temperature difference Teze minus Tpre observed at 0300 LST, 0900 LST, 1500 LST and 2100 LST. The curves are monthly mean values for four different months of the year.

The hyperbolic tangent distributes the land-river temperature difference symmetrically with respect to the coasts. In the present study the parameter $B$ is set equal to 1000 meters, which provides $75 \%(90 \%)$ of the temperature change over a distance of $2 B(3 B)$ across the coasts. Different $B$ values were tested and the adopted one minimized the averaged error of the wind distribution. Fig. 4 shows an example of $F_{2}(x, y)$ as a function of the perpendicular distance to the coast, across a narrow band centered at the coastline. Over the river and away from the coast, the surface temperature $T(x, y, t)=T_{o}$ remains constant, since $F_{2}(x, y)=0$. Over land and away from the coast the surface temperature develops a full 
daily cycle given by $T(x, y, t)=T_{o}+F_{1}(t)$, since $F_{2}(x, y)=1$. At the lateral boundaries all forecast variables, except pressure, are allowed to change in order to provide a zero gradient across the boundaries at each time step.

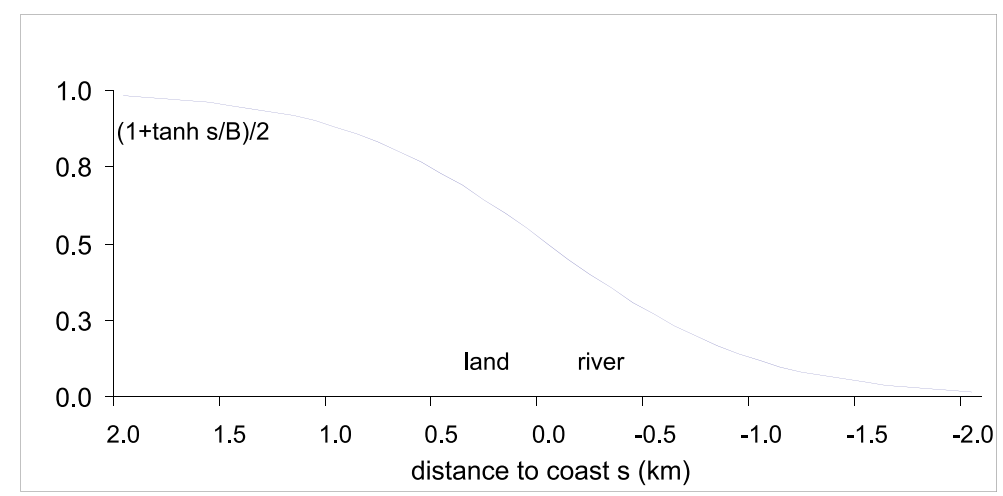

Fig. 4. Example of $F_{2}(x, y)$ as a function of the perpendicular distance to the coast, across a narrow band centered at the coastline, with parameter $B=1000 \mathrm{~m}$.

\subsection{Model validation}

Each ensemble member provides a forecast of the horizontal wind components $u$ and $v$ at 10 $\mathrm{m}$, and contributes to the wind field climatology with a probability $p_{j}$ with $j=1$ to $n$ $(n=192)$. The $u$ and $v$ forecast is expressed as a wind direction $d$ (degrees from the north), and a wind speed $v=\left(u^{2}+v^{2}\right)^{1 / 2}$ in $\mathrm{m} \mathrm{s}^{-1}$. The wind direction $d$ defines the wind sector identified by index $i=1$ to 9 (clockwise from $\mathrm{N}-i=1$ - until NW $-i=8-$ ), with $i=9$ indicating calm, i.e. wind speeds smaller than a given threshold discussed later on. Matrices $D_{i, j}^{k}$ and $V_{i, j}^{k}$ store the wind direction and wind speed forecasts, respectively, in which index $k=1$ to 4 represents the local time 0300, 0900, 1500 and 2100 LST, respectively.

Thus, the wind direction forecast simply consists of the occurrence of a given wind sector and matrix $D_{i, j}^{k}$ counts the number of cases. Once the $j$ th ensemble member forecast is completed, the quantity $p_{j}$ is added to the $(i, j, k)$ component of matrix $D_{i, j}^{k}$, and the quantity $v . p_{j}$ is added to the $(i, j, k)$ component of matrix $V_{i, j}^{k}$. After completing the series of forecasts, the elements of matrix $D_{i, j}^{k}$ are either zero or $p_{j}$, and $\sum_{i=1}^{9} \sum_{j=1}^{n} D_{i, j}^{k}=1$, since $\sum_{j=1}^{n} p_{j}=1$. At every $j$ th and $k$ th element of matrices $D_{i, j}^{k}$ and $V_{i, j}^{k}$, only one of the nine ith elements is not zero, i.e. the one that corresponds to the occurring wind direction sector.

At every grid point, the wind direction frequency distribution $f_{i}^{k}$ obtained with the model (in percentage) is:

$$
f_{i}^{k}=100 \cdot \sum_{j=1}^{n} D_{i, j}^{k}
$$

and the corresponding mean wind speed per wind sector $v_{i}^{k}\left(\right.$ in $\left.\mathrm{ms}^{-1}\right)$ is: 


$$
v_{i}^{k}=\sum_{j=1}^{n} V_{i, j}^{k} / \sum_{j=1}^{n} D_{i, j}^{k}
$$

since the $V_{i, j}^{k}$ elements are of the form $v \cdot p_{j}$, and the $D_{i, j}^{k}$ elements are of the form $p_{j}$.

The relative error in wind direction is defined as $e d_{i}^{k}=\left(f_{i}^{k}-f_{0}{ }^{k}\right) / f_{o_{i}}^{k}$ and in wind speed as $e v_{i}^{k}=\left(v_{i}^{k}-v o_{i}^{k}\right) / v o_{i}^{k}$. In these expressions $f_{0}^{k}$ and $v o_{i}^{k}$ are the mean observed wind direction frequency distribution and mean wind speed per wind sector, respectively, at the five surface weather stations of the study. The model distributions $f_{i}^{k}$ and $v_{i}^{k}$ are calculated with the averaged value of the four grid points that surround every weather station.

The averaged model errors are expressed as the root mean squared value of the relative error (from now on referred to as RMS), in wind direction $E r D^{k}$, from Equation (11), and wind speed $\operatorname{ErV} V^{k}$, from Equation (12), both weighted by the mean observed wind direction frequency $f_{0}^{k}$, as follows:

$$
\begin{aligned}
& \operatorname{ErD}^{k}=\left[\sum_{i=1}^{9} f o_{i}^{k}\left(e d_{i}^{k}\right)^{2} / \sum_{i=1}^{9} f_{0}{ }_{i}\right]^{1 / 2} \\
& \operatorname{ErV}^{k}=\left[\sum_{i=1}^{9} f o_{i}^{k}\left(e v_{i}^{k}\right)^{2} / \sum_{i=1}^{9} f o_{i}^{k}\right]^{1 / 2}
\end{aligned}
$$

\section{BLM low-level wind climatology}

\subsection{Annual mean}

Fig. 5 presents the wind direction frequency distribution and averaged wind speed by sector, obtained with the model according to Equations (11) and (12) (one every six grid points are plotted). It represents the averaged value of the four times of the day, when the observations are available in the database of the period 1959-1984. Since the model is initialized with the observations at 0900 LST, the 6-hour forecast is validated at 1500 LST, the 12-hour forecast at 2100 LST and the 18-hour forecast at 0300 LST. The 0900 LST forecast is taken after 30-minute integration in order to allow for the model spin-up.

The weather stations report the observed wind direction in eight compass sectors, and a ninth category that corresponds to calm wind, which means that the wind speed is below the instrument threshold. For the purpose of model validation, a calm wind observation represents a problem since the model never predicts a zero wind speed. Calm wind observations over the region are variable and depend on the weather station and time of the day, and in occasions they exceed a $30 \%$ of the observations. Thus, the inappropriate handling of the calm wind predictions may have a significant impact in the model errors, so it was necessary to adopt a criterion in order to overcome the problem. Test runs were conducted with the model with the purpose of determining the wind speed value below which the resultant percentage of calm winds would match the observations at the nearby weather station. This matching value was then adopted as the wind speed threshold below which the model result would be considered as calm wind. The thresholds varied depending on the time of the day and the position of the weather station in the domain. The nearby grid points to the 
weather stations over land displayed similar results, although with values always greater than those of the grid points nearby the river weather stations. The set of wind speed thresholds adopted for the grid points over land (in $\mathrm{m} \mathrm{s}^{-1}$ ) is: 1.6, 2.6, 1.4 and 1.4 at 0300, 0900, 1500 and 2100 LST, respectively. For the grid points over the river the wind speed thresholds (in m s $\mathrm{m}^{-1}$ ) are: $0.6,0.8,0.8$ and 0.6 , at $0300,0900,1500$ and 2100 LST, respectively.

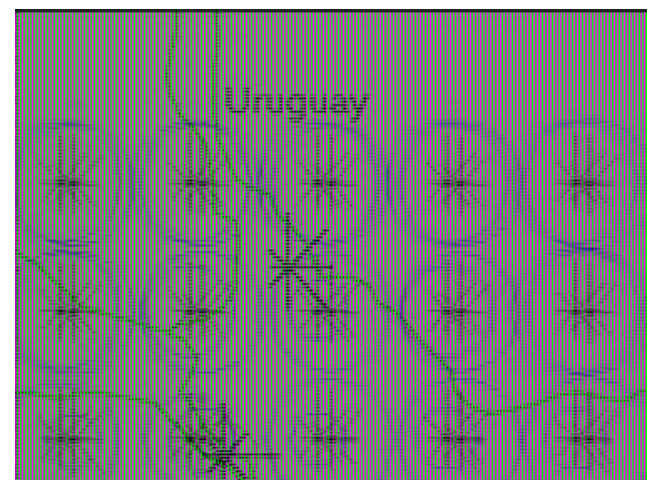

a) mean wind direction frequency

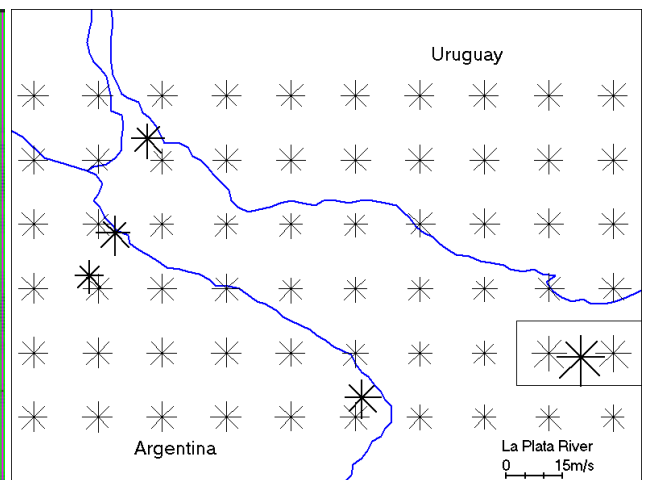

b) mean wind speed $\left(\mathrm{m} \mathrm{s}^{-1}\right)$

Fig. 5. a) mean wind direction frequency in percentage, and b) mean wind speed by sector in $\mathrm{m} \mathrm{s}^{-1}$ at $10 \mathrm{~m}$. Model results are plotted in thin lines and observations of the five weather stations of the study are plotted in thick lines. Circles of panel a) represent the frequency of calm wind (see text for details). The rectangular box on the right hand side of panel $b$ ) surrounds the model grid points that are plotted at $21 \mathrm{~m}$. (see text for details). The averaging period is $1959-1984$.

The wind sectors with higher frequencies obtained with the model are N, NE, E, SE and S, in coincidence with the observations (Fig. 5a). However, the dominant wind sectors vary according to the position over the domain and, in general; there is more contrast between points closer to the coasts and over the river. Over land and far away from the river, $\mathrm{N}$ and $\mathrm{NE}$ are, in this order, the wind sectors that display the higher frequencies. Over the river the wind direction distributions are different than over land and the E and SE wind sectors become, depending on the position, the dominant ones. The only two weather stations in the river are located at both ends, MGA at the river spring and PRE at the river mouth, so it is not possible to verify the model results along the river. For example, the wind direction distribution obtained with the model over the river centerline resembles the PRE observations, i.e. relatively high frequencies of the E and SE wind directions. However, the model results over the river mouth, with $\mathrm{N}$ and $\mathrm{NE}$ dominant wind directions, differ from the PRE observations with predominantly E and SE wind directions. This may be due to the fact that the grid points over this area are far away from the coast and have, therefore, less influence of the river-land surface thermal contrast. At the other end of the river the wind directions obtained with the model have a better agreement with the MGA observations. Over land there are only three weather stations with available observations for the study. The wind direction distributions obtained with the model agree better with the observations at EZE and PIN, than at AER. The first two weather stations are located a few tens of kilometers away from the coast, whereas AER is so close to it (about five hundred meters), that the horizontal resolution of the model may be a limiting factor. 
Fig. $5 b)$ shows the averaged wind speed by sector obtained with the model, as well as the observed wind speed at the five weather stations of the study. The wind instrument at PRE is at 21 meters above the surface so that the model grid points within the rectangular box on the right hand side of Fig. 5b) are plotted at that height. Throughout the domain, the model wind speeds are in general slightly greater in the S, SW and W wind sectors, in comparison with the others. The observations display a similar pattern, with the exception of PIN that shows less difference among wind sectors. There is also a general agreement between the magnitude of the observed and the modeled wind speeds, with the exception of the neighboring points to PRE where the observed wind speeds are clearly greater.

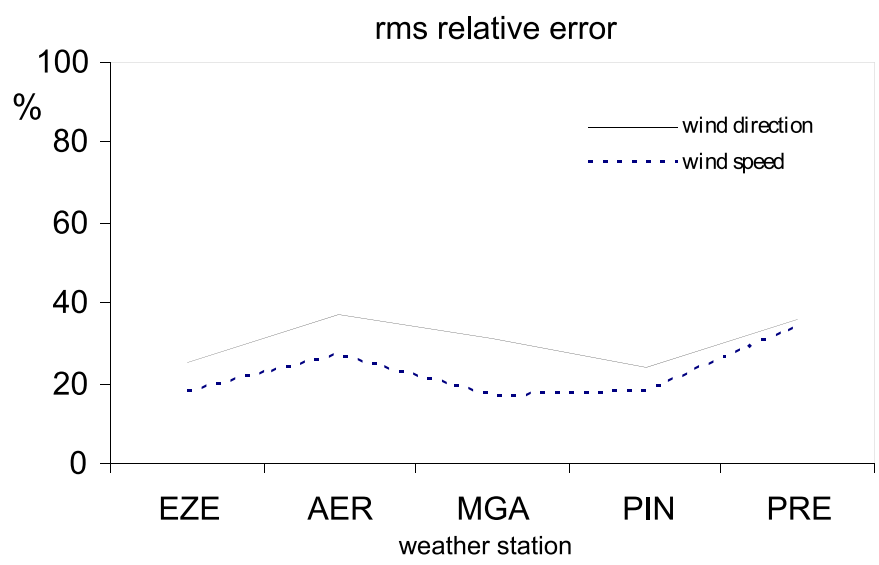

Fig. 6. Percentage RMS of the model relative errors in wind direction (Equation 13) and wind speed (Equation 14), averaged over the four grid points that surround every weather station: Ezeiza (EZE), Aeroparque (AER), Martín García (MGA), Punta Indio (PIN) and Pontón Recalada (PRE). The averaging period is 1959-1984.

Fig. 6 shows the percentage RMS of relative errors produced by the model in wind direction and wind speed, according to Equations (13) and (14) respectively, averaged over the four grid points that surround every weather station. At the five weather stations the error in wind speed is smaller than the error in wind direction. As discussed in the previous paragraph, the largest errors occur at PRE, while the smallest ones are at EZE and PIN. AER and MGA display errors with intermediate values in comparison with the other weather stations. The smallest errors are obtained at the weather stations located over land and away from the coast; because AER, also over land but very close to the coast, shows the second greatest error of the five weather stations. As mentioned above, the model resolution of 5 $\mathrm{km}$ may be the limiting factor responsible for the relatively large wind errors at AER.

The surface wind direction frequency distribution obtained with the model at four times of the day is shown in Fig. 7, together with the local observations. The regions along the river and over land near the coasts display more variability of the dominant wind sectors throughout the day. For example at 0900 LST (Fig. 7b), the dominant wind sectors are $\mathrm{N}$ and NE, while at 1500 LST (Fig. 7c) they are E and SE. This change is well represented by the model, particularly the shift towards the E sector, while the SE sector is more dominant over the central part of the river. Another particular aspect at the river mouth is the significant 
change in the dominant wind direction throughout the day, since the $\mathrm{N}$ and NE sectors at 0300 LST (Fig. 7a) and 0900 LST (Fig. 7b) become E, SE and S at 1500 LST (Fig. 7c) and at 2100 LST (Fig. 7d), which is reasonably well reproduced by the model. At the river spring, MGA shows predominance of the N and NE sectors at 0900 LST (Fig. 7b), in coincidence with the model results. At 1500 LST (Fig. 7c), MGA displays the S, N and SE as the dominant sectors, while the model shows the N, NE and SE sectors around MGA, with increasing frequency of the $\mathrm{SE}$ and $\mathrm{S}$ wind sectors towards the centerline of the river.

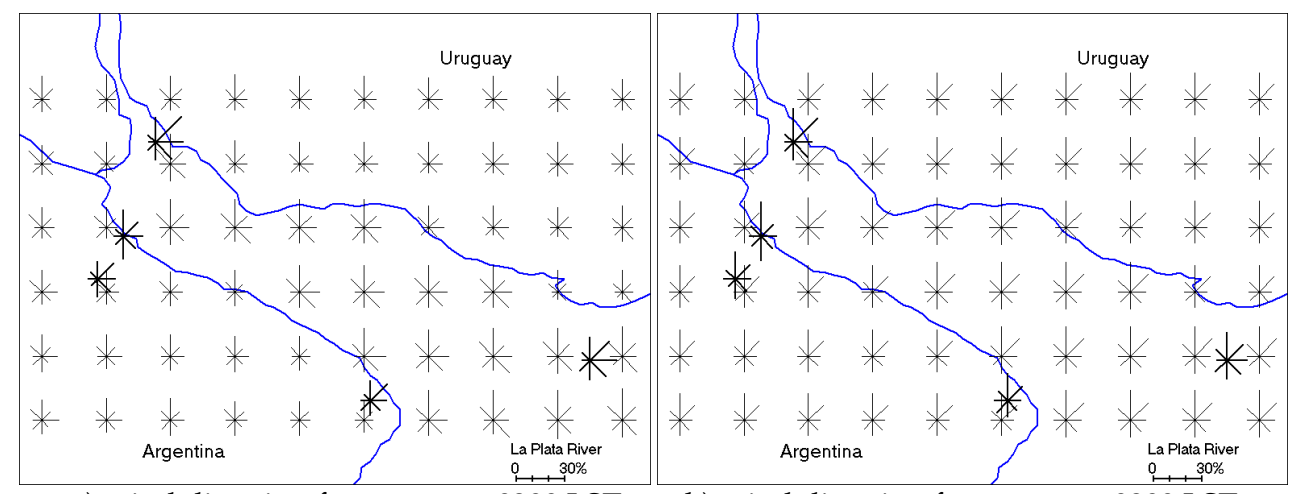

a) wind direction frequency at 0300 LST

b) wind direction frequency at 0900 LST

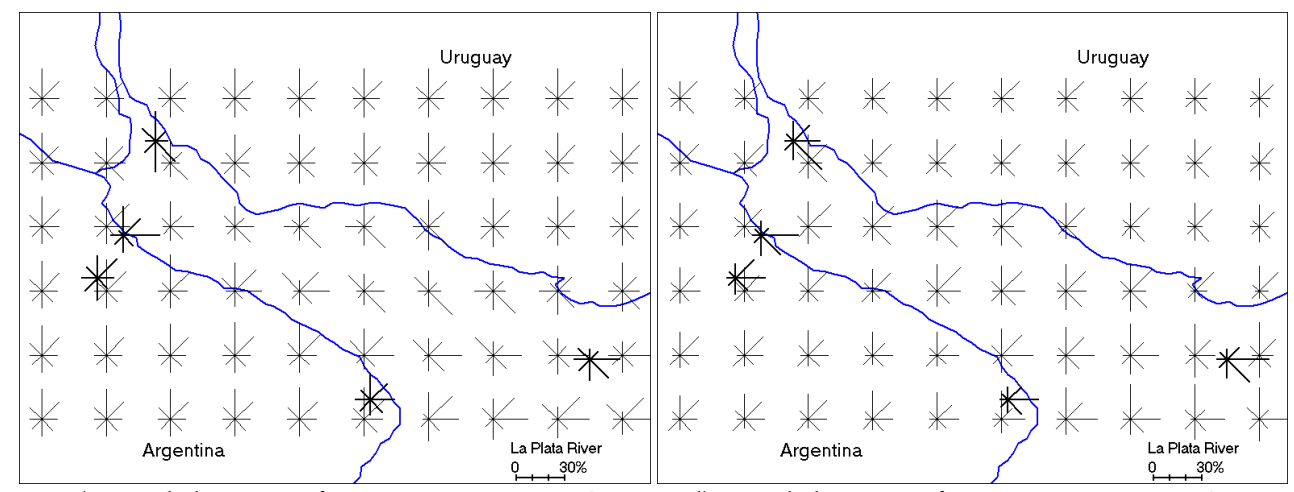

c) wind direction frequency at 1500 LST

d) wind direction frequency at 2100 LST

Fig. 7. Mean wind direction frequency by sector obtained with the model -thin lines-, and observed at the five weather stations of the study -thick lines- at $10 \mathrm{~m}$. at a) $0300 \mathrm{LST}, \mathrm{b}$ ) 0900 LST, c) 1500 LST and d) 2100 LST. The north wind direction points upward and each tick mark of the scale in lower right corner represents a $10 \%$ frequency. The averaging period is 1959-1984.

At 2100 LST (Fig. 7d) the MGA observations display the predominance of the SE, E and NE sectors, and the model agrees in the case of the SE and NE sectors, while the presence of E winds becomes more evident at the centerline and towards the river mouth. Over land at 0900 LST (Fig. 7b) the dominant sectors are N and NE, in agreement with the model results. At 1500 LST (Fig. 7c) the AER observations show the highest frequency in the E sector, but the model indicates the NE sector. There is also good agreement of the model results with 
the observations at EZE in the N and NE wind sectors, and at PIN in the N, NE and E wind sectors. At 2100 LST (Fig. 7d) the observations show an overall predominance of the E and SE sectors, in agreement with the model results, although the latter displays a significant $\mathrm{N}$ frequency, particularly towards the river mouth, that is not revealed by the observations. At 0300 LST (Fig. 7d) the observations show the N, NE, E and SE sectors as the dominant ones, while the model agrees with the $\mathrm{N}$ and $\mathrm{E}$ sectors, in general, although the NE frequency is relatively small in particular over the river and over land near the coast.

Fig. 8 shows the mean surface wind speed by sector obtained with the model, together with the observations of the five weather stations of the study at four times of the day. As indicated before, the grid points that surround PRE (rectangular box on the right hand side of each panel) are plotted at 21 meters above the surface in coincidence with the height of the wind instrument. In general, and throughout the domain, the observed and modeled mean wind speeds of all sectors are quite similar.

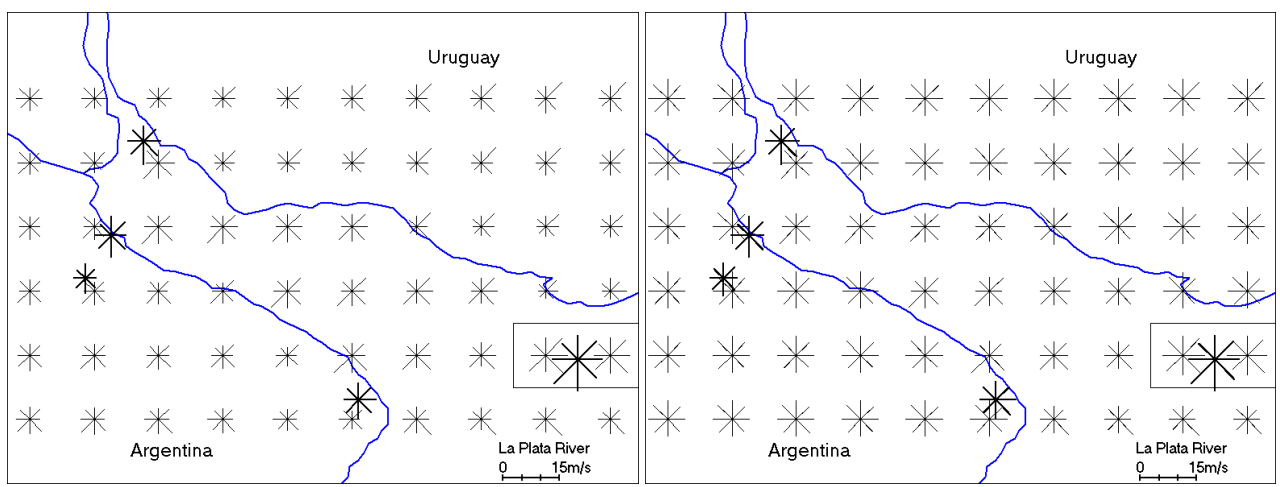

a) mean wind speed $\left(\mathrm{m} \mathrm{s}^{-1}\right)$ at 0300 LST

b) mean wind speed $\left(\mathrm{m} \mathrm{s}^{-1}\right)$ at 0900 LST

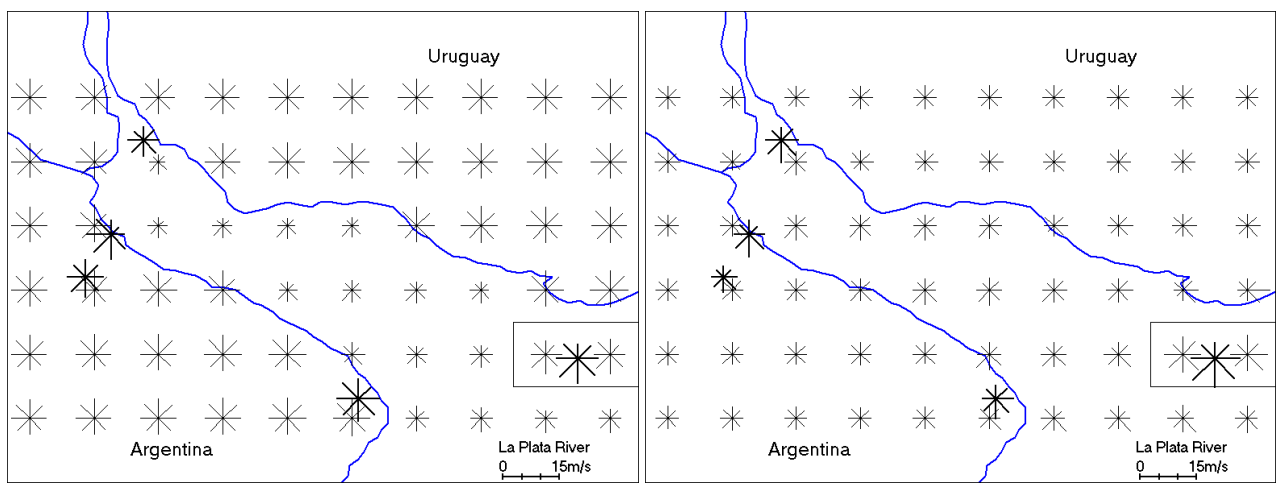

c) mean wind speed $\left(\mathrm{m} \mathrm{s}^{-1}\right)$ at 1500 LST

d) mean wind speed $\left(\mathrm{m} \mathrm{s}^{-1}\right)$ at 2100 LST

Fig. 8. Mean wind speed by sector obtained with the model -thin lines-, and observed at the five weather stations of the study -thick lines- at $10 \mathrm{~m}$. at a) 0300 LST, b) 0900 LST, c) 1500 LST and d) 2100 LST. The rectangular box on the right hand side of each panel surrounds the model grid points that are plotted at $21 \mathrm{~m}$. (see text for details). Each tick mark of the scale in lower right corner represents $5 \mathrm{~m} \mathrm{~s}^{-1}$. The averaging period is 1959-1984. 
The major observed contrast is between the wind speeds over the river and over land. For instance, at 0300 LST the wind speed over the river is clearly larger than over land, but at 1500 LST the situation is the opposite and the wind speed over land is significantly greater than over the river. At 0900 LST and 2100 LST the wind speed contrast between land and river is minimum. This spatial pattern and the changes that take place throughout the day is confirmed by the observations.

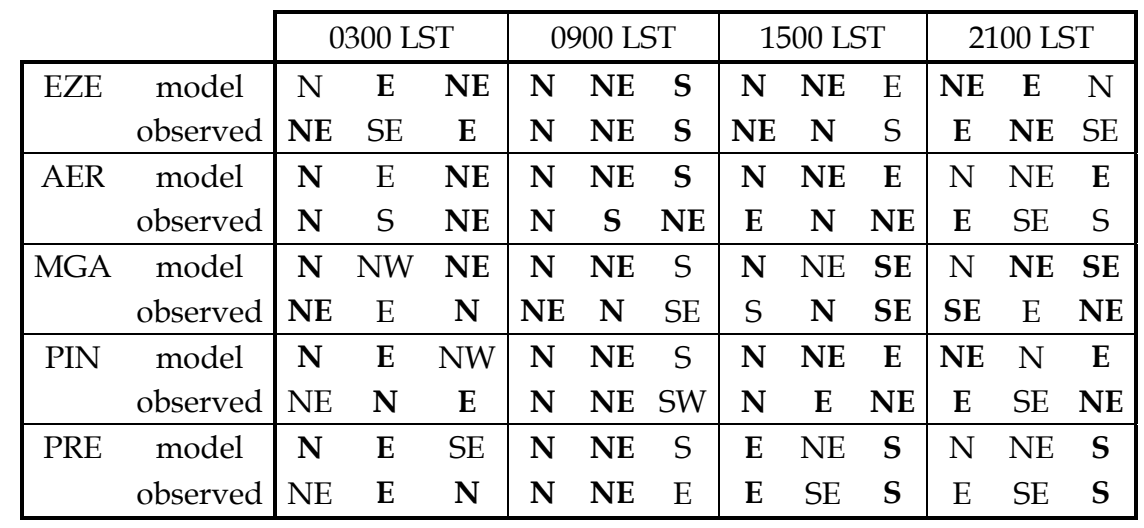

Table 2. First three observed and modeled wind sectors with highest frequency, in decreasing order, at the five weather stations of the study as a function of time of the day. In bold face are shown the matching wind direction sectors, regardless of their order.

Another way of comparing the model results with the observations is by analyzing the coincidence of the wind direction sectors with highest frequency. Table 2 lists the first three observed and modeled wind sectors with highest frequency, in decreasing order, that together amount $40 \%$ to $60 \%$ of the observations. For example, the upper-left box (EZE at 0300 LST) displays the NE, SE and E as the first, second and third wind sectors with highest frequency, whereas the model indicates $\mathrm{N}, \mathrm{E}$ and $\mathrm{NE}$, respectively.

The modeled and observed wind sectors that match are shown in bold face, regardless of the order in which they agree, since in some cases the ranking is defined by a few percent points. The best situation is when the three sectors match in the same order, as for example at 0900 LST at EZE, whereas the worst case is at 2100 LST at AER, when only the highest observed frequency is captured by the model but in third place. There is better agreement at the five points at 0900 LST and 1500 LST, since the average number of hits is 2.4, whereas at 0300 LST and 2100 LST the average number of hits is 1.6. At PRE the model shows less overall agreement with the observed predominant wind directions, since the average number of hits is 1.75. At the other four locations the model presents a similar behavior, at EZE, AER and PIN the average number of is 2.25 and at MGA is 2.0. In particular AER shows contrasting results because is the only place with twice three hits, i.e. at 0900 LST and 1500 LST, while at 2100 LST shows only one hit.

The model errors are not constant throughout the day, as can be seen in Fig. 9 that shows the percentage RMS of relative error, averaged of the five weather stations. Except at 0900 LST and 1500 LST, the wind speed error is much smaller than the wind direction error, and shows a minor dependence on the time of the day. The error in wind direction varies more throughout 
the day; it is minimum at 0900 LST and maximum at 2100 LST. The time evolution of the model errors does not follow a straightforward deterioration with time since the 13-hour (2100 LST) forecast error is larger than the 19-hour (0300 LST) forecast error.

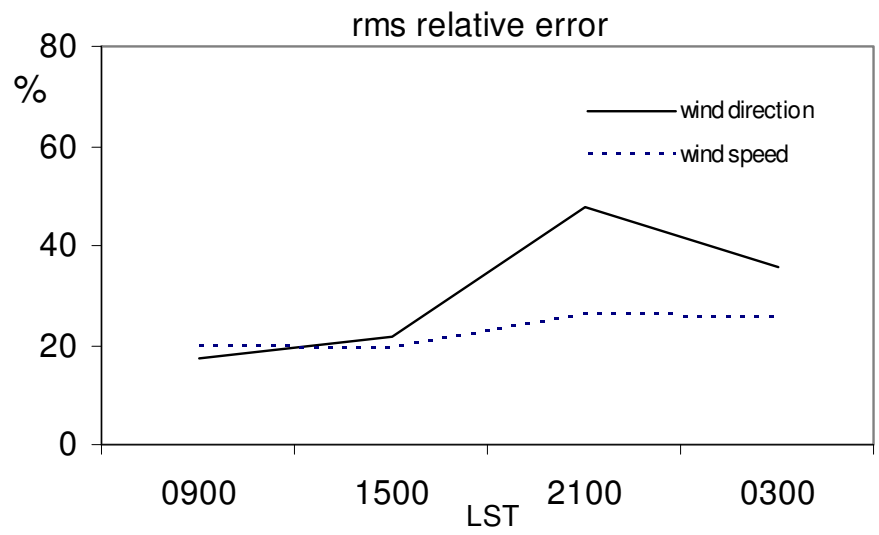

Fig. 9. Percentage RMS of the model relative errors in wind direction (Equation 13) and wind speed (Equation 14), as a function of the local standard time, averaged of the five weather stations. The averaging period is 1959-1984.

Fig. 10 shows the model errors in wind direction (top panel) and wind speed (bottom panel) as a function of weather station and time of the day. As mentioned before, wind direction errors (Fig. 10a) are more variable with time and space than wind speed errors (Fig. 10b). At 0900 LST and 1500 LST wind direction errors are minima and very small everywhere, while at 0300 LST and 2100 LST they are generally at their maxima, particularly at AER and PRE. At MGA the wind direction error shows a small variation throughout the day. On the other hand PRE, that has the greatest combined error in wind direction and wind speed (see Fig. 6) and displays strong daily variations, presents the minimum wind direction error at 0900 LST. The wind speed errors (Fig. 10b) are more homogeneous throughout the domain and present a similar variation with time of the day at the five weather stations.

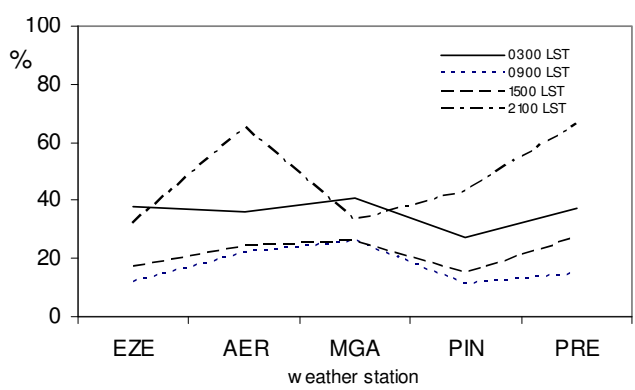

a) rms relative error wind direction

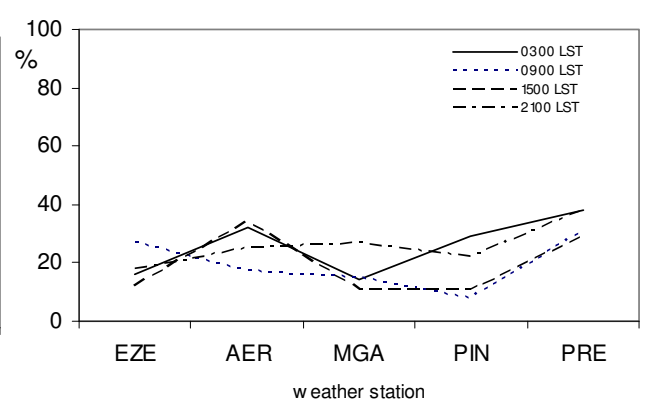

b) rms relative error wind speed

Fig. 10. Percentage RMS of the model relative errors in a) wind direction (Equation 13) and b) wind speed (Equation 14), averaged of the four grid points that surround every weather station: Ezeiza (EZE), Aeroparque (AER), Martín García (MGA), Punta Indio (PIN) and Pontón Recalada (PRE). The averaging period is 1959-1984. 


\subsection{Seasonal mean}

In order to assess the seasonal performance of the model, the same methodology as described in Section 3.1 is applied to the four seasons of the year defined as summer -DJF-, autumn -MAM, winter -JJA- and spring SON. Fig. 11 shows the model errors at the five weather stations as a function of the season of the year for wind direction (top panel) and wind speed (bottom panel). In the case of wind direction (Fig. 11a), the model error is minimum in winter and maximum in summer at the five locations. In spring the model errors are smaller that in autumn and the annual error is very similar to that of winter. The only exception is PRE where the autumn wind direction error is smaller than the annual one. The spread of the wind direction errors among the different seasons is similar at the five weather stations. The wind speed errors (Fig. 11b) display no seasonality, except in a minor degree in the case of EZE that has the minimum in summer and the maximum in winter and autumn, in contrast with the case of the wind direction error.

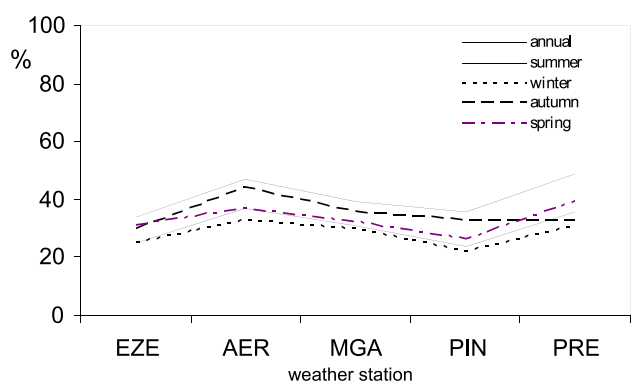

a) rms relative error wind direction

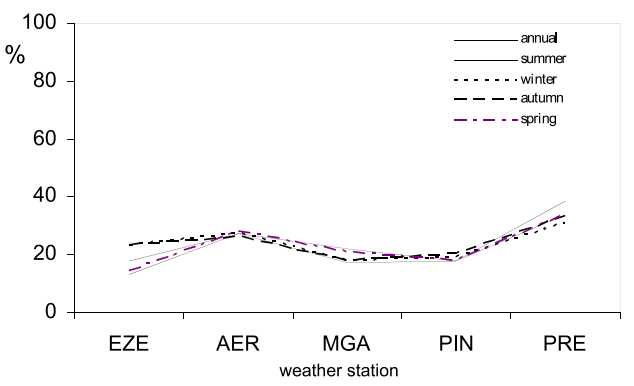

b) rms relative error wind speed

Fig. 11. Percentage RMS of the model relative errors as a function of season of the year, in a) wind direction (Equation 13) and b) wind speed (Equation 14). Values are the average of the four grid points that surround every weather station: Ezeiza (EZE), Aeroparque (AER), Martín García (MGA), Punta Indio (PIN) and Pontón Recalada (PRE). The averaging period is $1959-1984$.

\section{Validation of the synthesized method}

Normally, the climatological mean value of any meteorological variable is calculated by averaging all available observations. In the case of a model climatology the same concept applies, so that the climatological mean value should be the result of averaging a long series of individual realizations. The question is: how good is the "ensemble method" for calculating the low level climatological wind field in comparison with a conventional method based on individual daily forecasts?. Berri et al. (2011) address this question by calculating the climatological wind field in two different ways and comparing results with the observations. For this purpose, the same model version and data set period are employed. In one case, namely the "ensemble method", the climatological wind field is calculated, as described in Section 3, and in detail in Berri et al. (2010); as the average of 192 members and their associated probabilities. In the other case, namely the "daily method", the climatological wind field is calculated as the average of 3248 days with available data during the same period 1959-84. The resulting wind frequency distributions, as well as the observed one, are calculated in a similar manner. The objective is to evaluate the goodness 
of the ensemble method to synthesizing low level climatological wind fields, based on a reduced number of realizations, in comparison with the conventional method that employs a long series of individual realizations.

\subsection{Results of the validation}

Fig. 12 compares the averaged daily RMSEs of the low level wind climatology obtained with both methods, at the five meteorological stations of the study. Except at PRE, at the other stations the wind direction RMSE (panel a) of the daily method (dashed line) is a few percent points greater than that of the ensemble method (solid line). In the case of wind speed, panel b) shows almost no difference between the two methods.

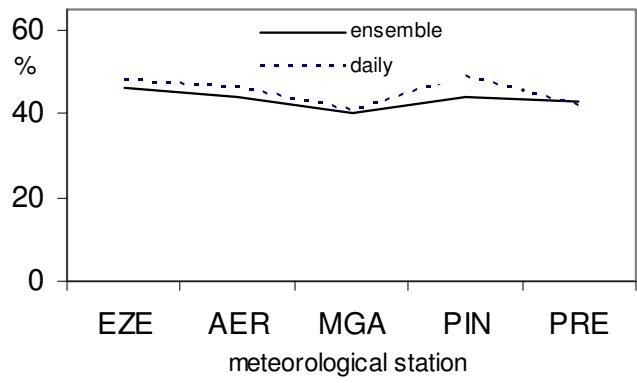

a) wind direction RMSE

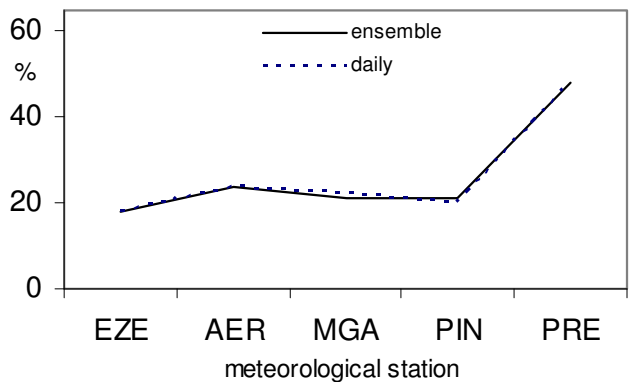

b) wind speed RMSE

Fig. 12. Ensemble method and daily method RMSEs, in percentage, at the meteorological stations of Ezeiza (EZE), Aeroparque (AER), Martín García (MGA), Punta Indio (PIN) and Pontón Recalada (PRE), averaged during the period 1959-1984. Panel a) corresponds to wind direction and panel b) corresponds to wind speed.

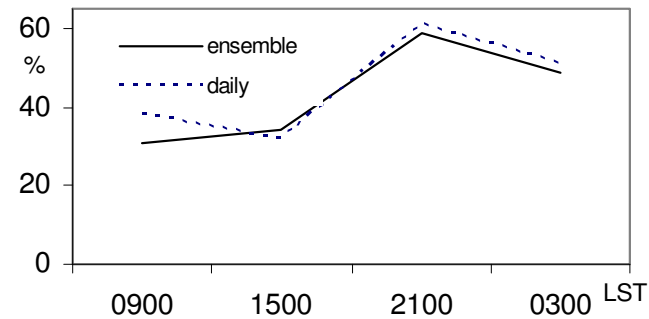

a) wind direction RMSE

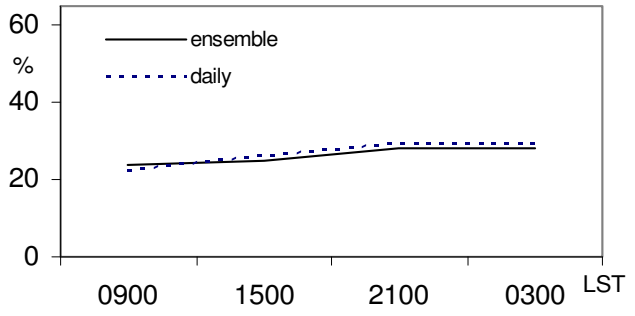

b) wind speed RMSE

Fig. 13. Ensemble method and daily method RMSEs, in percentage, as a function of the local standard time (LST), averaged over the five meteorological stations during the period 19591984. Panel a) corresponds to wind direction and panel b) corresponds to wind speed.

The RMSE of the two methods, averaged over the five meteorological stations and as a function of the local standard time, is compared in Fig. 13. In the case of wind direction (panel a), the ensemble method (solid line) has smaller RMSE in all cases except at 1500 LST. The largest difference in RMSE between the two methods is at 0900 LST, being smaller that of the ensemble method (solid line). In the case of wind speed (panel b), the ensemble method has smaller RMSE than the daily method, except at 0900 LST, although the differences are always of a few percent points. 
The comparison between the RMSE of both methods is shown in more detail in Fig. 14, by time of the day and meteorological station. In the case of wind direction (black line), EZE (Fig. 14a) and PIN (Fig. 14b) are the sites where at all times the ensemble method (solid line) has smaller RMSE. The largest differences in favour of the daily method (dashed line) are obtained for AER (Fig. 14b) at 1500 LST and MGA (Fig. 14c) at 0300 LST, i.e. 13 and 9 percent points, respectively. In the case of PRE (Fig. 14e), the daily method (dashed line) gives smaller RMSE at 1500 and 2100 LST.

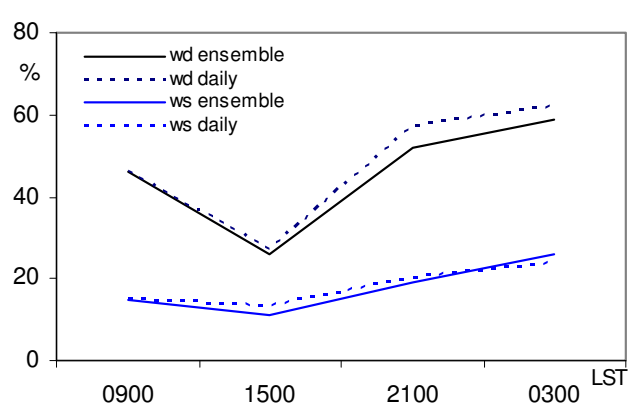

a) EZE RMSE

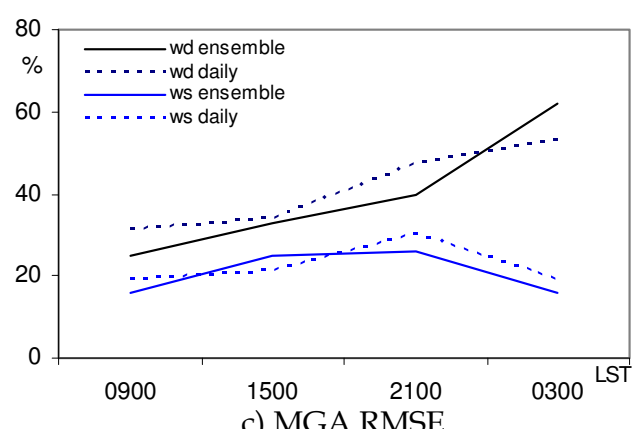

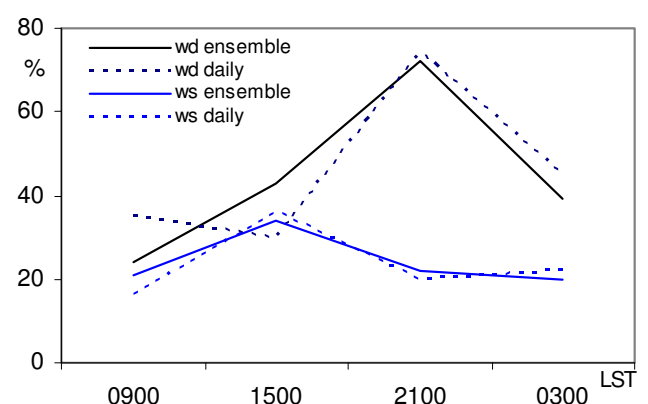

b) AER RMSE

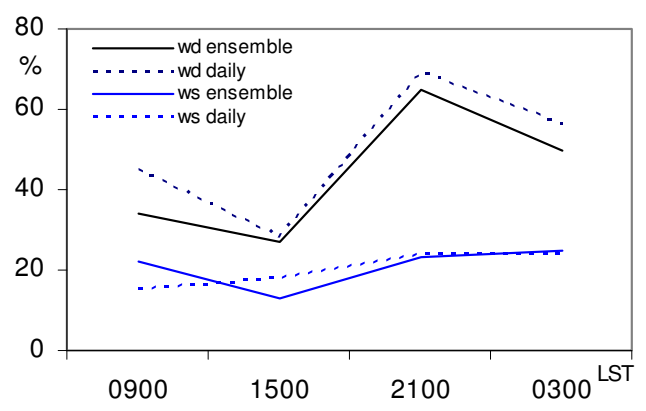

d) PIN RMSE

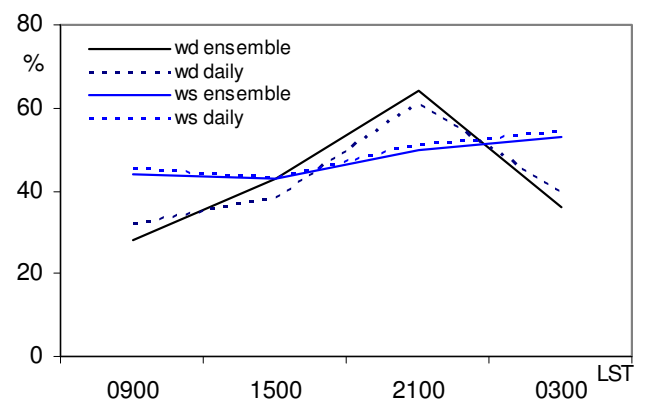

c) PRE RMSE

Fig. 14. Ensemble method and daily method RMSEs, in percentage, as a function of the local standard time (LST), at the five meteorological stations during the period 1959-1984. Wind direction (speed) RMSEs are shown in black (blue). 
In the case of wind speed (blue line), PRE (Fig. 14e) is the only site where at all times the ensemble method (solid line) has smaller RMSE, although by one percent point. PIN (Fig. 14d) and AER (Fig. 14b) show two times of the day with smaller RMSE for the daily method (dashed line), reaching 7 percent points in the case of PIN at 0900 LST. Finally, MGA (Fig. 14c) and EZE (Fig. 14a) present only one time of the day with smaller RMSE for the daily method (dashed line).

A qualitative summary of results is shown in Table 3 that presents the RMSE difference daily minus ensemble method. Considering individual boxes, $75 \%$ of them have greater or equal than zero values, meaning equal or better results with the ensemble method. When the wind direction and wind speed are considered together, the ensemble method shows smaller RMSE in $50 \%$ of the cases; while the daily method shows no cases like those.

Despite the fact that the ensemble method has, in general, smaller error; in some cases the wind direction RMSE of the daily method is small enough to overcome a larger RMSE in wind speed. In these situations the daily method has a smaller combined error; outperforming the ensemble method. The most notable cases are MGA at 0300 LST and AER at 1500 LST.

\begin{tabular}{|c|cc|cc|cc|cc|cc|}
\cline { 2 - 10 } \multicolumn{1}{c|}{} & \multicolumn{2}{c|}{ EZE } & \multicolumn{2}{c|}{ AER } & \multicolumn{2}{c|}{ MGA } & \multicolumn{2}{c|}{ PIN } & \multicolumn{2}{c|}{ PRE } \\
\hline LST & wd & ws & wd & ws & wd & ws & wd & Ws & wd & ws \\
0300 & 3 & -2 & 6 & 2 & -9 & 3 & 6 & -1 & 3 & 1 \\
0900 & 0 & 0 & 11 & -5 & 6 & 3 & 11 & -7 & 4 & 1 \\
1500 & 1 & 2 & -13 & 2 & 1 & -4 & 1 & 5 & -5 & 0 \\
2100 & 5 & 1 & 2 & -2 & 7 & 4 & 4 & 1 & -3 & 1 \\
\hline
\end{tabular}

Table 3. Absolute difference daily method minus ensemble method RMSE (in percent points) for wind direction (wd) and wind speed (ws), as a function of the local standard time (LST) at the meteorological stations of Ezeiza (EZE), Aeroparque (AER), Martín García (MGA), Punta Indio (PIN) and Pontón Recalada (PRE); averaged during the period 19591984. Positive numbers indicate smaller RMSE for the ensemble method.

The combined wind direction and wind speed error is largest at the evening (2100 LST). Berri et al. (2010) argued that the maximum error of the ensemble method at 2100 LST could be due to the fact that the transition from unstable daytime conditions to stable night time conditions takes place around that time of the day. In summer, 2100 LST is just after sunset; while in winter is about three hours after sunset. Since the ensemble method averages the surface conditions of different days with the same upper boundary condition, there could be an inherent limitation for appropriately resolving the transition from unstable to stable conditions. Therefore, the daily method would offer the possibility of overcoming such limitation by considering the individuality of each day of the data base. However, the present study indicates that this is not the case since the results of the daily method are not better than those of the ensemble method at 2100 LST. In the average, the results of the ensemble method are not outperformed by the daily method.

\section{Operational low-level wind forecast}

In order to test the BLM capability to produce operational low-level wind field forecasts over the La Plata River region, with higher temporal and spatial resolution than the 
presently available one, three experiments were conducted using different boundary conditions (see Sraibman \& Berri, 2009 for the details). In Experiment I the BLM model is forced in both the upper and lower boundaries with the forecasts of the Eta/CPTEC (Centro de Previsao de Tempo e Estudos Climáticos, Brazil) model (Mesinger \& Black, 1992). In Experiment II the BLM is forced in the upper boundary with the Eta model forecasts and in the lower boundary with the observed surface temperature. Experiment III employs only observations for defining the forcing conditions of the upper boundary (radiosonde data) and the lower boundary (surface temperature). In each experiment the BLM wind forecasts are compared to the available observational data and to the Eta model wind forecasts.

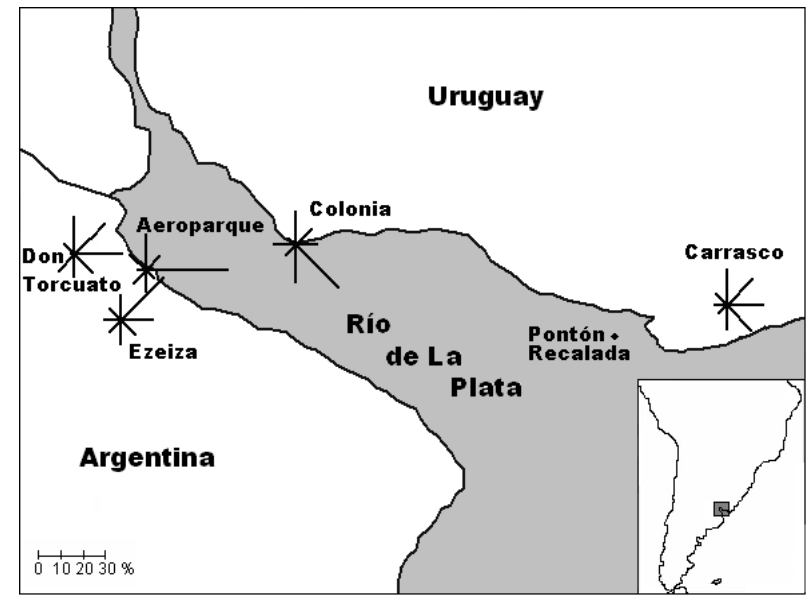

Fig. 15. Mean observed wind roses for the period November 2003-April 2004 at the meteorological stations Aeroparque, Don Torcuato, Ezeiza, Colonia and Carrasco. The scale in the lower left corner indicates the wind direction frequency in percentage

\subsection{Experiment design}

Each experiment consists of 142 diurnal forecasts obtained with the BLM model during the summer semester period of November 2003 to April 2004. The number of cases is less than the 182 days of that period of time, since the set of forecasts is restricted to those days with complete hourly observations. Each set member is a 12-hour forecast starting at 0900 local standard time (LST), approximately 2 to 3 hours after sunrise, when there is a minimum land-river temperature contrast. In this first study of BLM operational forecast verification, the forecast horizon is limited to the diurnal cycle, since the results of Berri \& Nuñez (1993) show that the most remarkable changes of the wind pattern take place during that part of the day. The forecast wind is compared to the observed wind in five weather stations in the region, Aeroparque, Don Torcuato and Ezeiza in Argentina and Colonia and Carrasco in Uruguay (see Fig.15 for their location). The 0900 LST BLM forecast is after 30 minutes of model integration, in order to facilitate the model spin-up. Fig. 15 shows the observed mean wind direction frequencies at the five weather stations of the study for the period November 2003-April 2004. The figure displays significant differences in the predominant wind direction sectors across the La Plata River region, as a consequence of the dominant sea-land breeze circulation. 


\subsection{Evaluation method}

The BLM and Eta model 10-m wind forecasts are validated with observations at the weatherstations, by means of two accuracy measures. One is the hit rate (HR) that counts the percentage of cases that the forecast wind direction matches the observed wind direction (Wilks, 1995), and the other one is the root-mean-squared error (RMSE) of the horizontal wind components.

In order to calculate the HR, the horizontal wind components are transformed to a wind direction expressed as one of the eight standard compass sectors (north, north-east, east, etc.). The RMSE is a usual accuracy measure employed in forecast verification (for example Hanna \& Yang 2001; White et al. 1999; Zhong \& Fast 2003), and is calculated as

$$
R M S E=\sqrt{\frac{1}{N}\left(\sum_{j=1}^{N}\left(u_{o}-u_{f}\right)_{j}^{2}+\sum_{j=1}^{N}\left(v_{o}-v_{f}\right)_{j}^{2}\right)}
$$

where $N$ is the number of available observations, $u$ and $v$ are the zonal and meridional wind components, respectively, subscripts $f$ and $o$ refer to forecast and observation, respectively, and subscript $j$ identifies the observation to be verified. The BLM forecasts are verified with each available observation between 0900 and 2100 LST, while the Eta forecasts are verified with the 0900, 1500 and 2100 LST observations, since these are the only model outputs available for the study. Since the terrain is flat, the verification of both models is made with the interpolated value of the four surrounding grid points to each weather station (the interpolation uses the same technique that is described in Section 5.3.1).

\subsection{Experiment I}

In this set of forecasts the BLM is forced at the upper and lower boundaries with the Eta forecasts; the Eta model produces twice daily forecasts initialized at 1200 UTC and 0000 UTC (corresponding to 0900 LST and 2100 LST, respectively). In the present study we use the 1200 UTC forecast of the previous day, since, according to Mesinger \& Black (1992), Seluchi \& Chou (2001) and Bustamante et al. (1999), the Eta forecasts for the second $24 \mathrm{~h}$ are better than for the first $24 \mathrm{~h}$. Thus, the BLM is initialized at 0900 LST with a 24-h Eta forecast. Since the Eta forecasts are available at 6-h intervals (i.e. 1200 UTC, 1800 UTC and 0000 UTC), it is necessary to interpolate the data in time in order to define the boundary conditions at the 1-min BLM timestep. For this purpose a cubic spline interpolating polynomial (Cormier and Marsh 2001) is implemented, which has the property of being continuous and having first-order and second-order continuous derivatives. Additionally, it is necessary to interpolate the data in space from the $40-\mathrm{km}$ resolution of the Eta model to the $10-\mathrm{km}$ BLM resolution, with the technique described in the following subsection.

\subsubsection{Upper boundary interpolation}

The $850 \mathrm{hPa}$ Eta wind forecasts are interpolated using the Cressman method (Cressman, 1959). The first step consists of calculating the distance $D_{i j}{ }^{k}$ from each BLM grid point, identified by subscripts $i$ and $j$, to every Eta grid point, identified with the superscript $k$. This distance is given by $D_{i j}^{k 2}=\left(X_{k}-X_{i j}\right)^{2}+\left(Y_{k}-Y_{i j}\right)^{2}$, where $X_{i j}$ and $Y_{i j}$ are the longitude and latitude, respectively, of the BLM grid points, and $X_{k}$ and $Y_{k}$ are the longitude and latitude, 
respectively, of the Eta grid points. The second step consists of calculating the weighting factor of each grid point as follows: $W_{i j}{ }^{k}=N^{2}-D_{i j}{ }^{k 2} / N^{2}+D_{i j}{ }^{k 2}$, if $N \geq D_{i j}{ }^{k}$, and $W_{i j}=0$, if $N<D_{i j}{ }^{k} . N$ is a fixed value that, after testing the results of the interpolation, it was set equal to 0.4 degrees. Finally, the corresponding value of any variable at each BLM grid point is given by $V_{i j}=\sum_{k} V^{k} W_{i j}{ }^{k} / \sum_{k} W_{i j}^{k}$, where $V^{k}$ is the corresponding value at the Eta grid point.

\subsubsection{Lower boundary interpolation}

At the lower boundary a similar interpolating routine is implemented, although it is applied separately to the grid points over the land and over the river, respectively. The reason for this procedure is because the temperature over the river is quite homogeneous and changes in a very small amount during the day, while over land the temperature daily cycle is large, reaching values of up to $10^{\circ} \mathrm{C}$ or more. Thus, a $1-\mathrm{km}$ transition band centred at the coast is established, in which the land-river surface temperature difference is linearly interpolated. This provides a smooth transition between the two regions and concentrates the land-river temperature contrast at the coast.

\subsubsection{Results of experiment I}

Table 4 shows that the BLM RMSE is between 2.4 and $3.3 \mathrm{~m} \mathrm{~s}^{-1}$ smaller than the Eta RMSE, while the BLM HR value is almost three times the corresponding Eta value in all cases. The comparison of the HR obtained with both models at every weather station is shown in Fig. 16 at three different times of the day, as well as the average value of the three times. In all the weather stations the wind direction forecasts obtained with the BLM are better than those of the Eta model, and in particular at 0900 LST they provide the largest HR values. The improvement of the BLM forecasts over the Eta forecasts is greatest in Aeroparque, the closest weather station to the river shore.

The analysis of the BLM wind field forecast (not shown) revealed an excessive predominance of the inland wind component at 1500 LST, indicating a stronger than normal sea breeze. The BLM surface forcing is the land-river temperature difference, so that a large thermal contrast will induce a strong sea-land breeze circulation.

\begin{tabular}{|c|c|c|c|c|c|c|c|c|c|c|}
\hline & \multicolumn{2}{|c|}{0900 LST } & \multicolumn{2}{|c|}{1500 LST } & \multicolumn{2}{|c|}{2100 LST } & \multicolumn{2}{|c|}{$\begin{array}{l}\text { Average 0900, } \\
\text { 1500, } 2100 \text { LST }\end{array}$} & \multicolumn{2}{|c|}{$\begin{array}{c}\text { Average from } \\
0900 \text { to } 2100 \\
\text { LST }\end{array}$} \\
\hline & $\begin{array}{l}\mathrm{HR} \\
(\%)\end{array}$ & $\begin{array}{l}\text { RMSE } \\
\left(\mathrm{m} \mathrm{s}^{-1}\right)\end{array}$ & $\begin{array}{l}\text { HR } \\
(\%)\end{array}$ & $\begin{array}{l}\text { RMSE } \\
\left(\mathrm{m} \mathrm{s}^{-1}\right)\end{array}$ & $\begin{array}{l}\mathrm{HR} \\
(\%)\end{array}$ & $\begin{array}{l}\text { RMSE } \\
\left(\mathrm{m} \mathrm{s}^{-1}\right)\end{array}$ & $\begin{array}{l}\mathrm{HR} \\
(\%)\end{array}$ & $\begin{array}{l}\text { RMSE } \\
\left(\mathrm{m} \mathrm{s}^{-1}\right)\end{array}$ & $\begin{array}{l}\mathrm{HR} \\
(\%)\end{array}$ & $\begin{array}{l}\text { RMSE } \\
\left(\mathrm{m} \mathrm{s}^{-1}\right)\end{array}$ \\
\hline BLM & 68 & 3.2 & 50 & 3.5 & 58 & 3.6 & 59 & 3.4 & 58 & 3.5 \\
\hline Eta & 21 & 5.6 & 18 & 6.8 & 15 & 6.5 & 18 & 6.4 & & \\
\hline
\end{tabular}

Table 4. HR and RMSE for Experiment I

In order to compare the magnitude of the Eta model thermal contrast with observations, we calculate the temperature difference between Ezeiza (inland) and Pontón Recalada (river). We chose Ezeiza as the most representative inland weather station, since it is located several kilometres away from the coast, while Pontón Recalada is the only one weather station over the river (see Fig. 15). The observed temperature difference is 
compared to the temperature difference between the nearest Eta grid points to each of the above mentioned weather stations.

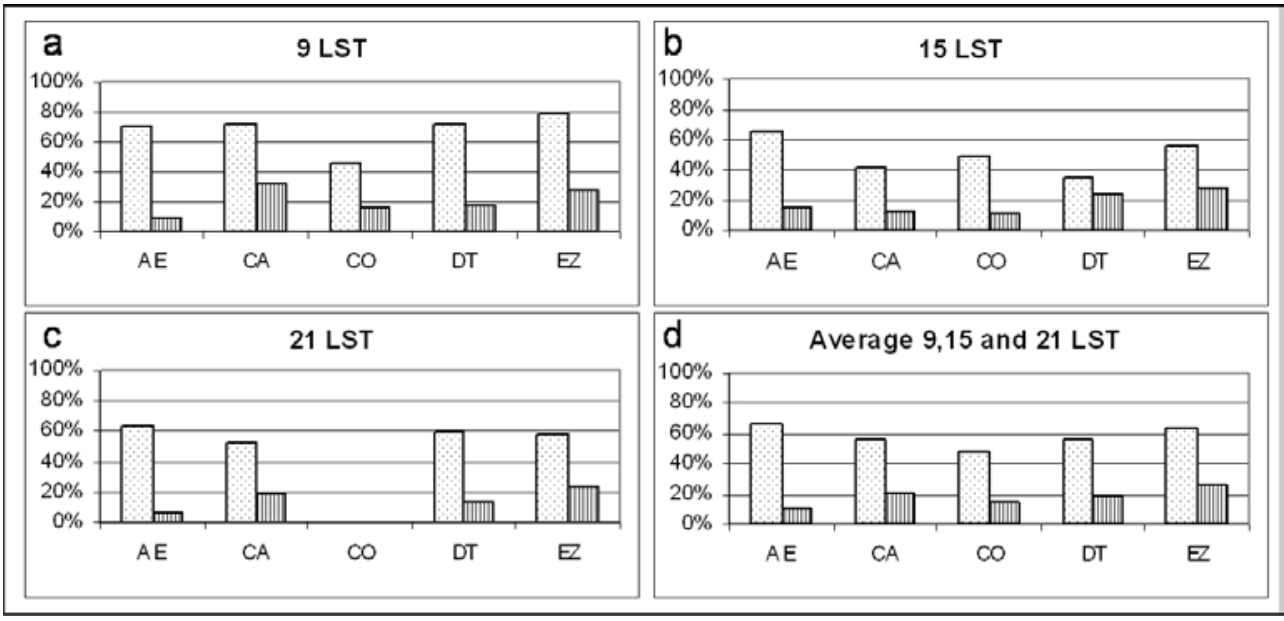

Fig. 16. HR rates for Experiment I at a) 0900 LST, b) 1500 LST, c) 2100 LST and d) average of 0900, 1500 and 2100 LST, for the meteorological stations Aeroparque (AE), Carrasco (CA), Colonia (CO), Don Torcuato (DT) and Ezeiza (EZ). The dotted (dashed) bar corresponds to the BLM (Eta) model.

The mean value of the observed temperature difference is $1^{\circ} \mathrm{C}, 4^{\circ} \mathrm{C}$ and $1^{\circ} \mathrm{C}$ (at 0900,1500 and 2100 LST, respectively), whereas the Eta forecast provides, respectively, the following values $1^{\circ} \mathrm{C}, 10^{\circ} \mathrm{C}$ and $-2^{\circ} \mathrm{C}$. The largest disagreement between observations and Eta forecasts of the land-river thermal contrast is in the afternoon, which is responsible for the stronger than normal sea breeze component. Therefore, with the purpose of improving the BLM forecast, a new experiment is designed in which the surface forcing is defined from the observations.

\begin{tabular}{|c|c|c|c|c|c|c|c|c|c|c|}
\hline & \multicolumn{2}{|c|}{0900 LST } & \multicolumn{2}{|c|}{1500 LST } & \multicolumn{2}{|c|}{2100 LST } & \multicolumn{2}{|c|}{$\begin{array}{l}\text { Average 0900, } \\
1500,2100 \text { LST }\end{array}$} & \multicolumn{2}{|c|}{$\begin{array}{c}\text { Average from } \\
0900 \text { to } 2100 \\
\text { LST }\end{array}$} \\
\hline & $\begin{array}{l}\text { HR } \\
(\%)\end{array}$ & $\begin{array}{l}\text { RMSE } \\
\left(\mathrm{m} \mathrm{s}^{-1}\right)\end{array}$ & $\begin{array}{l}\text { HR } \\
(\%)\end{array}$ & $\begin{array}{l}\text { RMSE } \\
\left(\mathrm{m} \mathrm{s}^{-1}\right)\end{array}$ & $\begin{array}{l}\text { HR } \\
(\%)\end{array}$ & $\begin{array}{l}\text { RMSE } \\
\left(\mathrm{m} \mathrm{s}^{-1}\right)\end{array}$ & $\begin{array}{l}\text { HR } \\
(\%)\end{array}$ & $\begin{array}{l}\text { RMSE } \\
\left(\mathrm{m} \mathrm{s}^{-1}\right)\end{array}$ & $\begin{array}{l}\mathrm{HR} \\
(\%)\end{array}$ & $\begin{array}{l}\text { RMSE } \\
\left(\mathrm{m} \mathrm{s}^{-1}\right)\end{array}$ \\
\hline BLM & 64 & 3.7 & 60 & 4.2 & 45 & 3.7 & 56 & 3.8 & 58 & 4.3 \\
\hline Eta & 21 & 5.6 & 18 & 6.8 & 15 & 6.5 & 18 & 6.4 & & \\
\hline
\end{tabular}

Table 5. HR and RMSE for Experiment II

\subsection{Experiment II}

In this case the BLM is forced by a surface potential temperature given by the expression: $\theta(x, y, t)=\theta_{0}+A(t)[1+\tanh (s(x, y) / B)]$, where $\theta_{0}$ is the mean value of the surface potential temperature over the entire domain at the initial state. The land-river temperature difference, $A(t)$, is calculated as the harmonic analysis of the observed temperature difference between 
Ezeiza and Pontón Recalada at 0300, 0900, 1500 and 2100 LST. Finally, $s(x, y)$ is the shortest distance from every grid point to the coast. The hyperbolic tangent distributes the land-river temperature difference symmetrically with respect to the coast and the parameter $B=1000 \mathrm{~m}$ provides $75 \%(90 \%)$ of the temperature change in a distance of $2 B(3 B)$ across the coast. The upper boundary condition of the BLM model is the same as Experiment I.

\subsubsection{Results of experiment II}

Table 5 compares the RMSE and HR values of both models, and again the BLM forecasts result more accurate than the Eta forecasts. However, the average results are not as good as those of Experiment I, since the average HR of $56 \%$ is slightly smaller than the $59 \%$ of Experiment I (see column 4), and the RMSE equal to $3.8 \mathrm{~m} \mathrm{~s}^{-1}$ is slightly larger than the 3.4 $\mathrm{m} \mathrm{s}^{-1}$ of Experiment I. However, when looking at different times of the day we can see that at 1500 LST the HR equal to $60 \%$ represents an improvement over the $50 \%$ of Experiment I, although the RMSE equal to $4.2 \mathrm{~m} \mathrm{~s}^{-1}$ is slightly worse than the $3.5 \mathrm{~m} \mathrm{~s}^{-1}$ of Experiment I. On the other hand, the BLM forecasts at 0900 and 2100 LST are degraded in comparison with Experiment I. For example the HR value drops from $68 \%$ to $64 \%$ at 0900 LST and from $58 \%$ to $45 \%$ at 2100 LST. Similarly, the RMSE increases from $3.2 \mathrm{~m} \mathrm{~s}^{-1}$ to 3.7 $\mathrm{m} \mathrm{s}^{-1}$ at 0900 LST and from $3.6 \mathrm{~m} \mathrm{~s}^{-1}$ to $3.7 \mathrm{~m} \mathrm{~s}^{-1}$ at 2100 LST. The improvement of the BLM afternoon forecasts is the result of a more appropriate definition of the land-river thermal contrast, since the excessive forcing obtained from the Eta forecast develops a much stronger inland sea breeze component. The last column of Tables 4 and 5 contains the average values of BLM HR and RMSE of all the hours between 0900 LST and 2100 LST, and Experiment I shows a slight improvement over Experiment II in the case of the RMSE, but not in the HR which has the same value. Clearly, a better definition of the surface forcing improves the BLM forecasts at 1500 LST.

Fig. 17 shows the HR value at each weather station and time of the day. It can be clearly seen that at 1500 LST (Fig. 17b), Experiment II has a better forecast performance than Experiment I, except at the Ezeiza weather station.

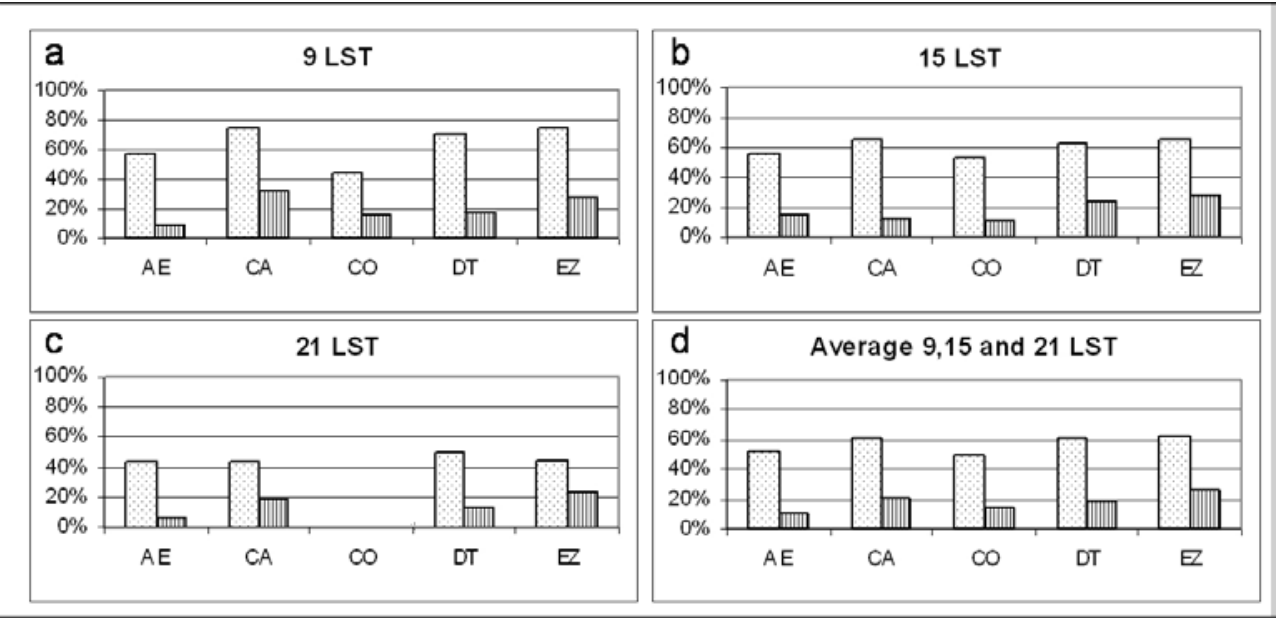

Fig. 17. same as Fig. 16, but for Experiment II. 


\begin{tabular}{|c|c|c|c|c|c|c|}
\hline & \multicolumn{2}{|c|}{$\begin{array}{c}\text { BLM boundary conditions } \\
\text { from Eta forecasts }\end{array}$} & \multicolumn{3}{|c|}{$\begin{array}{c}\text { BLM boundary conditions } \\
\text { from observations }\end{array}$} & \\
\hline $\begin{array}{c}\text { Upper } \\
\text { boundary }\end{array}$ & $\begin{array}{c}850 \mathrm{hPa} \text { Exp } \\
\text { I }\end{array}$ & $1000 \mathrm{hPa}$ & $850 \mathrm{hPa}$ & $925 \mathrm{hPa}$ & $\begin{array}{c}1000 \mathrm{hPa} \text { Exp } \\
\text { III }\end{array}$ & Eta \\
\cline { 1 - 6 } $\begin{array}{c}\text { Lower } \\
\text { boundary }\end{array}$ & $\begin{array}{c}\text { Eta } \\
\text { temperature }\end{array}$ & $\begin{array}{c}\text { Eta } \\
\text { temperature }\end{array}$ & $\begin{array}{c}\text { temperature } \\
\text { function }\end{array}$ & $\begin{array}{c}\text { temperature } \\
\text { function }\end{array}$ & $\begin{array}{c}\text { temperature } \\
\text { function }\end{array}$ & \\
\hline RMSE(m s-1) & 3.4 & 3.4 & 3.8 & 3.4 & 3.4 & 6.4 \\
\cline { 1 - 6 } HR (\%) & 59 & 53 & 41 & 48 & 64 & 18 \\
\hline
\end{tabular}

Table 6. Averaged 0900, 1500 and 2100 LST RMSE and HR values at the five meteorological stations, obtained with the Eta and the BLM models forecasts under different boundary conditions. Eta temperature means that the interpolation from Eta temperature is used, and temperature function means that the surface potential temperature function is used.

\subsection{Experiment III, model forced with observations}

In this case, both the upper and lower boundary conditions for the BLM forecasts are defined exclusively from the local observations. The surface forcing condition is the same as Experiment II, but the upper boundary condition is taken from the 1200 UTC (0900 LST) 850 $\mathrm{hPa}$ level Ezeiza radiosonde sounding. Since there is only one sounding a day, the upper boundary condition remains constant during the integration period.

\subsubsection{Results of experiment III}

Table 6 compares the averaged RMSE and HR values (0900, 1500 and 2100 LST) at the five weather stations obtained with the BLM forecasts performed with different boundary conditions. In the first two columns the boundary conditions are taken from the Eta forecasts (first column corresponds to Experiment I); while in the following three columns the boundary conditions are taken from the observations. The last column shows the averaged RMSE and HR values of the Eta forecasts. In all the cases the BLM forecasts are more accurate than the Eta forecasts, although there are remarkable differences among the different cases.

\begin{tabular}{|c|c|c|c|c|c|c|c|c|c|c|}
\hline & \multicolumn{2}{|c|}{0900 LST } & \multicolumn{2}{|c|}{1500 LST } & \multicolumn{2}{|c|}{2100 LST } & \multicolumn{2}{|c|}{$\begin{array}{l}\text { Average 0900, } \\
\text { 1500, } 2100 \text { LST }\end{array}$} & \multicolumn{2}{|c|}{$\begin{array}{c}\text { Average from } \\
0900 \text { to } 2100 \\
\text { LST }\end{array}$} \\
\hline & $\begin{array}{l}\text { HR } \\
(\%)\end{array}$ & $\begin{array}{l}\text { RMSE } \\
\left(\mathrm{m} \mathrm{s}^{-1}\right)\end{array}$ & $\begin{array}{l}\text { HR } \\
(\%)\end{array}$ & $\begin{array}{l}\text { RMSE } \\
\left(\mathrm{m} \mathrm{s}^{-1}\right)\end{array}$ & $\begin{array}{l}\text { HR } \\
(\%)\end{array}$ & $\begin{array}{l}\text { RMSE } \\
\left(\mathrm{m} \mathrm{s}^{-1}\right)\end{array}$ & $\begin{array}{l}\text { HR } \\
(\%)\end{array}$ & $\begin{array}{l}\text { RMSE } \\
\left(\mathrm{m} \mathrm{s}^{-1}\right)\end{array}$ & $\begin{array}{l}\text { HR } \\
(\%)\end{array}$ & $\begin{array}{l}\text { RMSE } \\
\left(\mathrm{m} \mathrm{s}^{-1}\right)\end{array}$ \\
\hline BLM & 73 & 3.0 & 64 & 3.7 & 54 & 3.7 & 64 & 3.4 & 62 & 3.3 \\
\hline Eta & 21 & 5.6 & 18 & 6.8 & 15 & 6.5 & 18 & 6.4 & & \\
\hline
\end{tabular}

Table 7. HR and RMSE for Experiment III 
When the $850 \mathrm{hPa}$ level of the radiosonde sounding is used as the upper boundary condition (same level of the Eta forecasts used in the previous case); the BLM forecasts degrade with respect to Experiment I, since the RMSE increases from $3.4 \mathrm{~m} \mathrm{~s}^{-1}$ to $3.8 \mathrm{~m} \mathrm{~s}^{-1}$ and the HR drops from $59 \%$ to $41 \%$ (Table 6 , column 3 ). In view of this, we decided to run the BLM forecasts using other levels of the radiosonde sounding for defining the upper boundary condition. The other two standard levels available in the observations are 925 $\mathrm{hPa}$ and $1000 \mathrm{hPa}$, and the results shown in columns 4 and 5 of Table 6 indicate that the forecast performance improves as the level of the boundary condition approaches the surface. The best result is obtained with the $1000 \mathrm{hPa}$ condition, which represents an improvement, although small, with respect to the case in which the Eta forecasts are used to define both boundary conditions, i.e. the RMSE remains unchanged but the HR increases from 59\% to $64 \%$ (Table 6, column 5). The La Plata River region is under the influence of the South Atlantic anticyclone whose temperature inversion defines the top of the boundary layer. The analysis of the Ezeiza radiosonde data shows that in $72 \%$ of the observations during the validation period, the base of the temperature inversion is below $850 \mathrm{hPa}$, and in $54 \%$ of the cases it is below $925 \mathrm{hPa}$. Therefore, most of the time those two levels are above the top of the boundary layer, which may be reason why the best results are obtained when forcing the model with an upper boundary condition taken from the $1000 \mathrm{hPa}$ level.

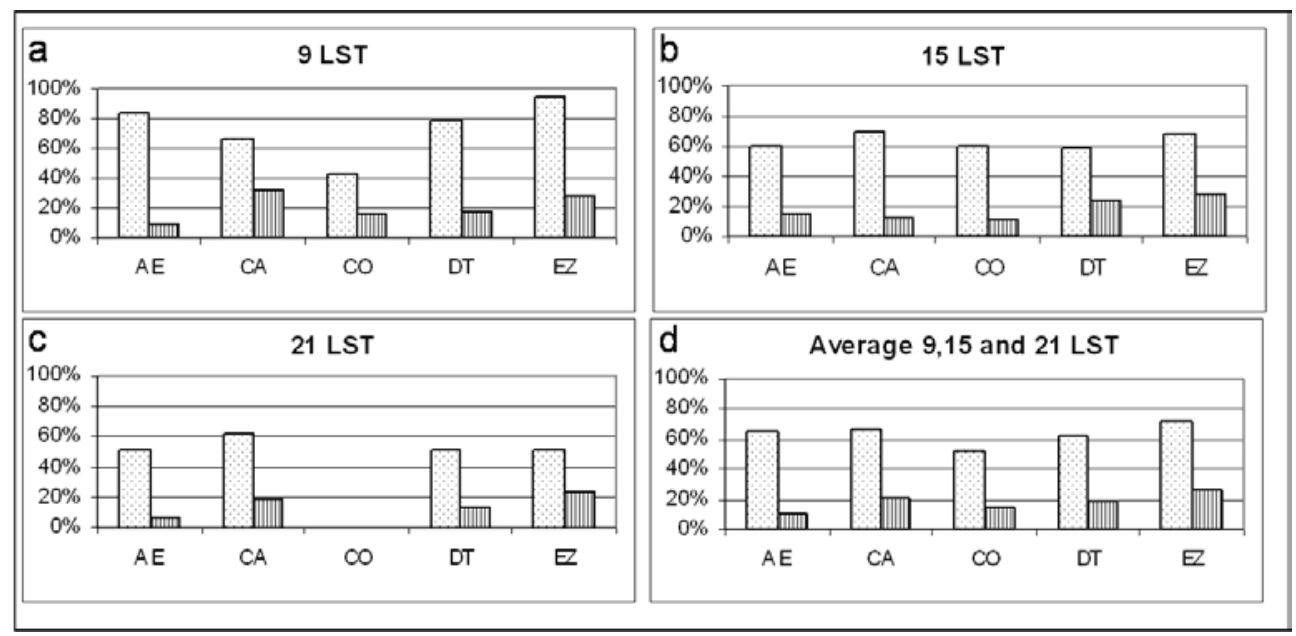

Fig. 18. same as Fig. 16, but for Experiment III.

Table 7 details the results of Experiment III and shows forecast degradation with time as in the two previous experiments. Fig. 18 shows that the HR obtained with the BLM at every weather station is, in the average, better than that of the Eta forecasts. When comparing the results of this experiment with the other two, the HR is always equal or better at every weather station, with the exception of Colonia. For comparison, the BLM is run with the upper boundary condition taken from the $1000 \mathrm{hPa}$ Eta forecasts (Table 6, column 2), but 
now the results worsen since the HR drops from $59 \%$ to $53 \%$, although the RMSE remains unchanged and equal to $3.4 \mathrm{~m} \mathrm{~s}^{-1}$.

Table 8 compares the results of the three experiments by time of the day. In the average (rightmost two columns), the results of Experiment III are better than those of the other two experiments in terms of both the HR and the RMSE. This is also the case at 0900 LST and 1500 LST. However, at 2100 LST Experiment I provides the best result, indicating that for longer lead times the use of forecast boundary conditions is better than the persistence of observations. Also, in all cases the BLM wind forecasts are more accurate than the Eta forecasts, for example the BLM RMSE is between $1.9 \mathrm{~m} \mathrm{~s}^{-1}$ and $3.3 \mathrm{~m} \mathrm{~s}^{-1}$ smaller than the Eta RMSE and the HR value is more than three times greater than that of the Eta forecasts. Table 8 also shows systematic forecast degradation with time in Experiment III, in which only observations are used for defining the boundary conditions. On the other hand, when only the Eta forecasts are used for defining the boundary conditions, i.e. Experiment I, the 12-hour (2100 LST) forecast results are not only slightly more accurate than the 6hour forecast, but they are also unmatched. These results indicate that for longer lead forecasts there is a clear advantage of using the Eta model outputs for defining the boundary conditions.

\subsection{Example of forecast for 18 January 2004}

Since point verification may not be well suited for quantifying forecast models, and only standard meteorological observations are available in the region, a qualitative measure of verification is implemented. The BLM vertical velocity forecast is compared to the cumulus cloud distribution of a satellite image, in order to give a regional scale assessment of the model ability. As an example, this section presents the forecast for 18 January 2004, a date that was chosen with the following consideration. A first screening identified the days with an $850-\mathrm{hPa}$ Eta forecast of light winds from the east or north-east throughout the daytime hours. This is the appropriate regional condition for the development of the typical low clouds that are induced by the sea-breeze circulation in the region. Out of the initially identified 7 days, the date of the example was the only one with a clear satellite image available around noon.

Firstly, the 10-m wind field forecasts of the BLM and Eta models are compared to the observations. Figure 19a shows the BLM forecast at 0900 LST along with the wind observations (thick arrows) at the five weather stations of the study (left panel), and the Eta forecast (right panel). The wind field for both models is mainly from the east and north-east, in agreement with the observations. However, there are discrepancies in the wind speeds since the Eta forecast around the weather stations in Argentina shows smaller values than the BLM forecast, which in turn agrees better with the observations. Besides, the BLM winds are weaker over the river and stronger over the land, whereas the Eta forecast shows systematically decreasing wind speeds from east to west.

Figure 19b corresponds to 1500 LST, the time of the day when the sea breeze is well developed. The Eta forecast shows south-easterly winds across the river and neighbouring regions, whereas the observations reveal different wind directions. Over the coastal region of Uruguay the BLM and the Eta wind direction forecasts are from the south-east, in agreement with the observations. Over the coastal region of Argentina the BLM wind 
direction forecast is east, which agrees with the observations, whereas the Eta wind direction forecast is south-east. The observed wind pattern over the region of the river springs displays the inland sea-breeze component, which is very well represented by the BLM forecast but clearly ignored by the Eta forecast. Figure 19c corresponds to 2100 LST, when the observed wind direction field over the coast of Uruguay does not show changes with respect to the 1500 LST forecast. The BLM wind direction forecast agrees with the observations, whereas the Eta forecast shows a wind direction shift to the eastern sector over the entire northern half of the region. Over the coast of Argentina the BLM forecast shows easterly and east-south-easterly winds, mostly in agreement with the observations. Instead, the counter-clockwise wind direction change from panel (b) to (c) of the Eta forecast is opposed to the observed one, between 1500 LST and 2100 LST.

The comparison of the wind fields at these three times clearly reveals the significant variability in time and space of the sea-land breeze circulation across the region. On the other hand, these changes are reasonably well represented by the BLM forecast, particularly over the river springs, but completely ignored by the Eta forecast. Figure 20a presents the forecast vertical velocity field at 1,200 m for 1100 LST, 18 January 2004. The regions identified with letters $\mathrm{A}$ and $\mathrm{E}$ display downward motion, whereas the rest of the domain displays upward motion. Since there are no vertical velocity observations available, it is possible to perform a qualitative verification of the vertical motion by analyzing the cumulus cloud distribution of a satellite image. Figure 20b shows the 1344 UTC (1044 LST) NOAA-17 satellite image, in which the low-level cumulus clouds can be clearly identified. The region identified with letter A in Fig. 20a matches the cloud free region over most of the river and the neighbouring inland region of Argentina of Fig. 20b. The region identified with letter B in Fig. 20a displays upward motion over land and up to the river shore, in coincidence with the cumulus cloud distribution in Fig. 20b, whereas in region $C$ the clouds are located further inland (Fig. 20b); in agreement with the vertical motion field of Fig. 20a. Over the river mouth (Fig. 20b) there are scattered clouds, again in agreement with the upward motion of region D in Fig. 20a. Region E (Fig. 20a), inland over Uruguay and far from the river, is characterized by downward motion, coinciding with a cloud free region in Fig. 20b. Region F is clearly the one without any qualitative agreement between cloudiness and vertical motion. There, the model results indicate upward motion, with a maximum near the coast, whereas the satellite image is free of clouds. One of the tributaries of the La Plata River is the Uruguay River, which can be clearly seen in the satellite image coming from the north. The other tributary is the Paraná River, which drains from the north-west (upper left corner of Fig. 20b), and despite having flow that double the flow of the Uruguay River, is not clearly visible in the image. This is because the Paraná River runs along multiple streams that form a river delta, merging the La Plata River immediately to the north-west of the city of Buenos Aires. Therefore, a significant part of region $\mathrm{F}$ is a very humid flatland where the river-land temperature contrast is not confined to a narrow region as in the rest of the La Plata River shores. This singularity modifies the convergence/divergence pattern of the horizontal motion and, consequently, the vertical motion as well. Since the BLM model does not consider different soil types, this particular characteristic of region $\mathrm{F}$ is not represented, which in turn may explain the disagreement between the observed cloud distribution and the predicted vertical motion. Figure 21 presents a vertical cross-section at $58.4 \circ \mathrm{W}$ of the BLM vertical velocity forecast for 1500LST. 

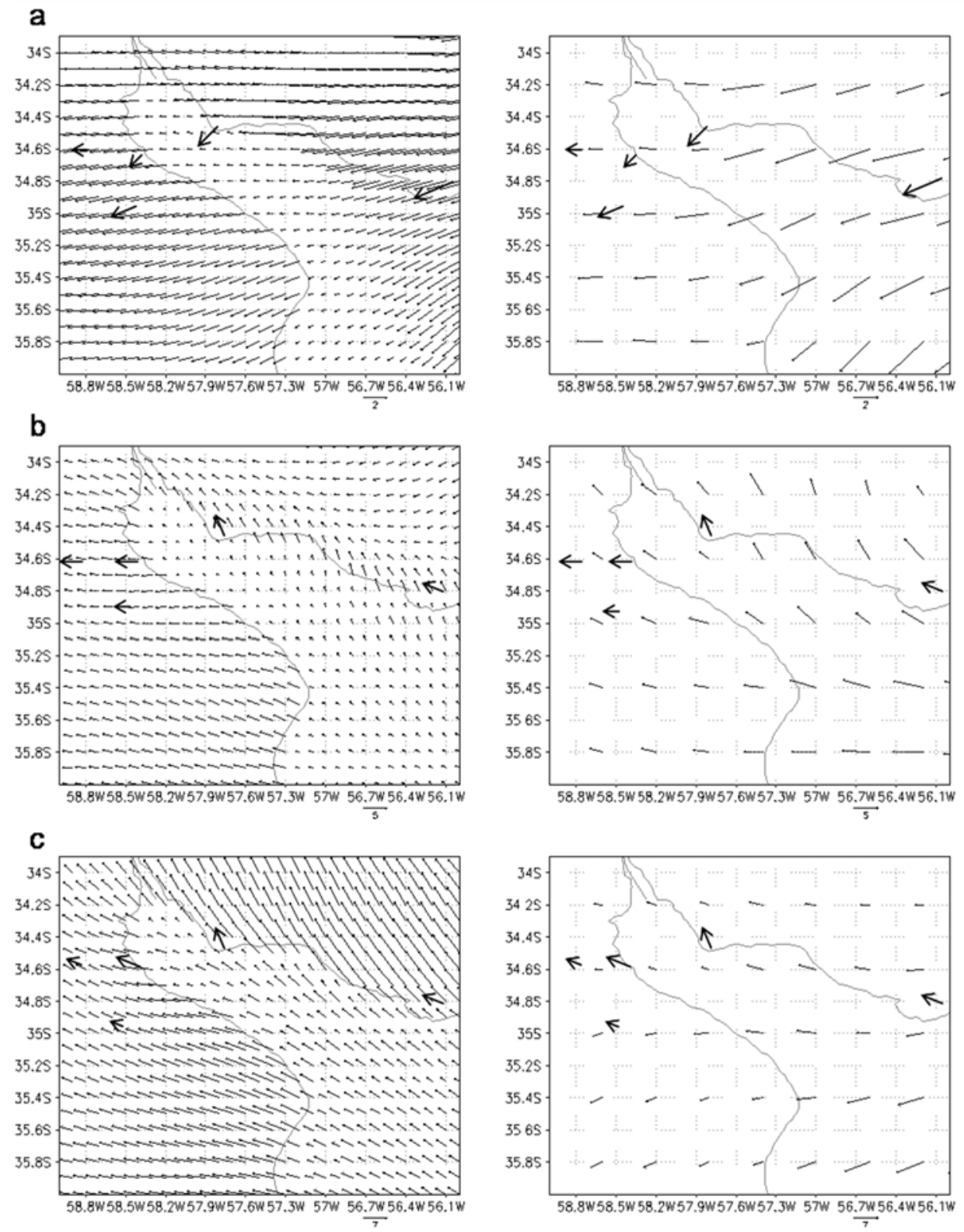

Fig. 19. Example of 10 meters wind field forecast of BLM model (left panels), and Eta model (right panels). The bold arrows represent the standard wind observations at the five weather stations. The date is 18 January 2004 and panel (a) corresponds to 0900 LST, panel (b) corresponds to 1500 LST and panel (c) corresponds to 2100 LST. 
At this time of the day the sea breeze is at its peak, so that the land regions display upward motion and the river region, at the centre of the figure, displays downward motion. This vertical velocity pattern is typical of a well-developed mid-afternoon sea-breeze circulation that results from the low-level wind convergence/divergence fields. A similar vertical crosssection of the Eta forecast (not shown) does not reveal any detail since the magnitude of the vertical motion is of the order of $0.1 \mathrm{~mm} \mathrm{~s}^{-1}$, with no clearly defined spatial pattern.

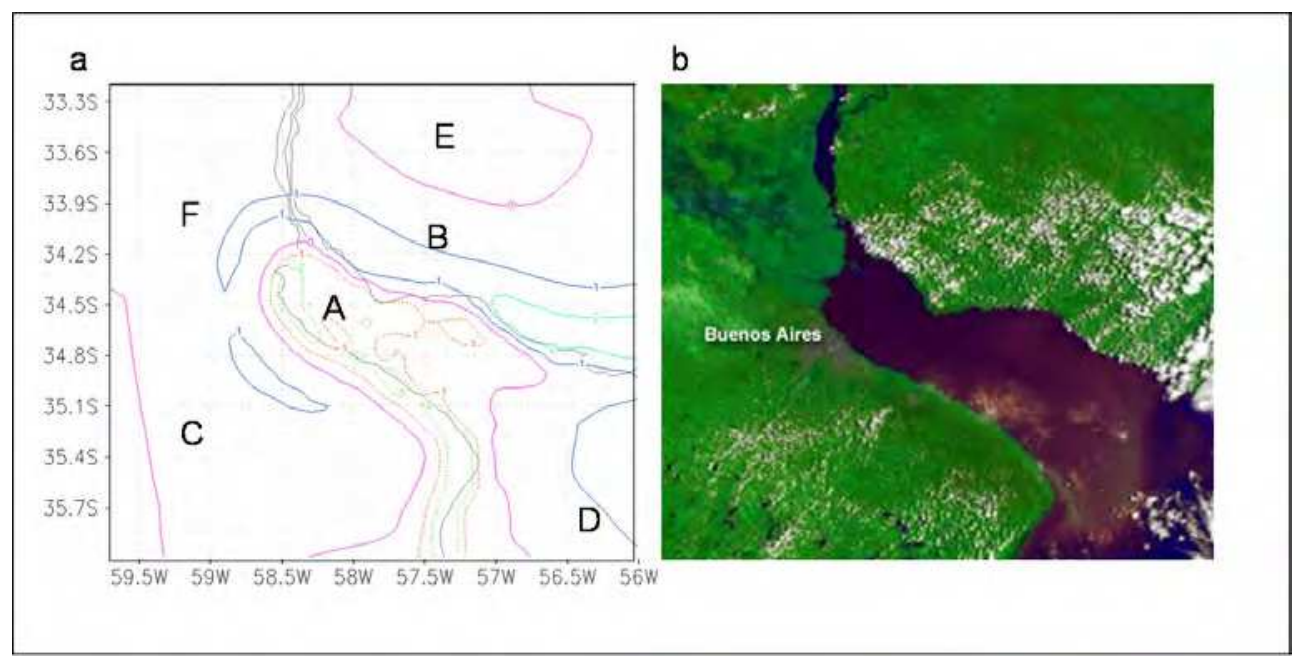

Fig. 20. (a) BLM vertical velocity forecast at $1200 \mathrm{~m}$ corresponding to 1100 LST of 18 January 2004; (b) NOAA-17 satellite image at 13:44 UTC (10:44 LST) provided by the National Meteorological Service of Argentina.

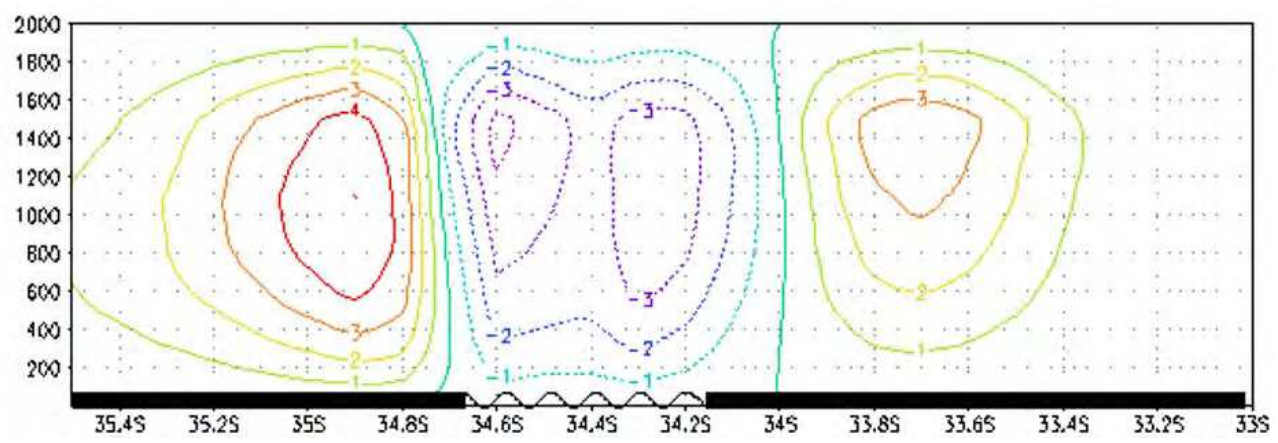

Fig. 21. Vertical cross section at $58.8^{\circ} \mathrm{W}$ of the BLM vertical velocity forecast $\left(\mathrm{cm} \mathrm{s}^{-1}\right)$ at 1500 LST. 


\subsection{Discussion of operational forecast validation}

In Experiment I the BLM is forced with the Eta 850-hPa wind forecasts at the upper boundary and the Eta surface temperature forecasts at the lower boundary. The BLM wind forecasts are substantially better than the Eta wind forecasts. The BLM RMSE is about $50 \%$ smaller, and the HR is more than three times greater, than the corresponding Eta forecasts. The river-land temperature differences forecast by the Eta model are always greater than the observed ones, the consequence of which is a degradation of the wind direction forecast, since the excessive thermal forcing creates a stronger than normal inland wind component during the afternoon. In view of this problem, Experiment II defines the surface forcing as a function of the observed temperature difference between Ezeiza (land) and Pontón Recalada (river) weather stations. The wind direction forecast is significantly better in the afternoon, although it is accompanied by a small degradation of the wind-speed forecast. On the other hand, the degradation of the wind direction forecast by the evening is larger than in Experiment I, indicating that the forecast improvement achieved during the first hours cannot be sustained with time.

Experiment III is designed to validate the BLM forecasts when forced exclusively with observations. The lower boundary condition is the same as in Experiment II, while the upper boundary condition is taken from the 0900 LST Ezeiza radiosonde sounding at the three standard levels within the boundary layer, i.e. 850, 925 and 1,000hPa. When the 850 and $925 \mathrm{hPa}$ levels are used, the forecast results are not better than those of Experiment I. Instead, the $1,000-\mathrm{hPa}$ level provides the best result since the error measures are the minimum of all experiments. The South Atlantic anticyclone has a strong influence over the La Plata River region and its temperature inversion defines the top of the boundary layer. The morning sounding reveals that most of the time the temperature inversion is below 925 $\mathrm{hPa}$, and this may be the reason why the best result is obtained when forcing the model at the upper boundary condition with the 1,000-hPa data.

The BLM forecasts show greater degradation with time when the boundary conditions are defined exclusively from the observations. On the other hand, when they are defined exclusively from the Eta forecasts, the 12-h forecasts are more accurate than the 6-h forecasts. This result clearly indicates the advantage of using the Eta model outputs for defining the boundary conditions for longer lead BLM forecasts.

Although the short lead forecasts improve when forcing the BLM with observations, this case has operational disadvantages. Since the model is forced with the only daily radiosonde sounding at 0900 LST, the synoptic scale changes that may take place during the forecast period are ignored. Also, the necessity of specifying the lower boundary forcing as a function of time would require a forecast of the land-river temperature difference, so that an additional uncertainty may affect the final result. In any case this method would allow for a 12-h forecast for the rest of the day, but, on the other hand, the use of 48-h Eta model outputs for forcing the BLM allows for a forecast with 1 day in advance, i.e. 36-h lead forecast.

As an additional measure of verification, the vertical velocity field forecast by the model is compared to the cumulus cloud distribution of a satellite image, in order to have a regional scale assessment of the model simulation. The result shows a good agreement between the 
spatial patterns inmost parts of the region, i.e. cumulus cloud areas (cloud free areas) coincide with the areas where the model predicts upward (downward) motion. The improvement of the low-level wind forecast obtained with the BLM model, in comparison to the Eta model forecast, is not a straightforward consequence of the higher horizontal resolution of the former, in terms of grid spacing. An additional experiment is performed in which the BLM is forced at the lower boundary with the Eta model surface temperature forecasts, with the following consideration. The Eta model outputs are simply interpolated to the BLM resolution, i.e. ignoring the coastal geometry as in all other experiments. The result, although representing a minor improvement over the Eta forecasts, is far from achieving the performance of Experiment I. It is clear that the advantage of using the BLM model for forecasting the low-level wind field over the La Plata River region is the result of a more appropriate definition of the land-river surface temperature contrast. The particular formulation that the BLM model has for the geometry of the river coasts is fundamental for resolving the smaller scale details of the low-level local circulation.

Despite the large errors in the surface winds displayed by the Eta forecasts, its $850-\mathrm{hPa}$ wind and surface temperature forecasts are able to drive the BLM model to obtain surface wind forecasts with smaller errors than the Eta model.

\section{Conclusion}

The conclusion is that the ensemble method is an appropriate methodology for determining high resolution, low level climatological wind fields, with the BLM model applied to a region with strong diurnal cycle of surface thermal contrast. The proposed methodology is of particular utility for synthesizing wind fields over regions with limited meteorological observations, since the 192-member matrix can be reasonably defined with few observing points, and even in the case of incomplete records. Also, operational low-level wind forecasts for the La Plata River region can be improved by forcing the BLM model with the Eta operational forecasts.

\section{Acknowledgements}

Partial support for this research was provided by research grants PIPs 5575 and 0772 from Consejo Nacional de Investigaciones Científicas y Técnicas (CONICET) of Argentina, and PICTs 2005/38193 and 2008/1417, from Agencia Nacional de Promoción Científica y Tecnológica of Argentina. Also acknowledged is the Servicio Meteorológico Nacional of Argentina for providing the meteorological station data, with special thanks to Jose Ares for preparing the data base.

\section{References}

Berri, G.J. (1987). Thermo-hydrodynamic study of the atmospheric boundary layer over the La Plata River region with a numerical simulation model, Doctoral Thesis, available at Department of Atmospheric and Oceanic Sciences, University of Buenos Aires.

Berri G.J. \& Nuñez M.N. (1993). Transformed shoreline-following horizontal coordinates in a mesoescale model: A sea-land breeze case study, J. Appl. Meteorol., 5, 918-928pp. 
Berri, G.J., L. Sraibman, R.A. Tanco \& G. Bertossa (2010). Low-level wind field climatology over the La Plata River region obtained with a mesoscale atmospheric boundary layer model forced with local weather observations. J. Appl. Meteorol., 49, 1293-1305

Berri, G.J., J. Galli Nuin, L. Sraibman \& G. Bertossa (2011). Verification of a synthesized method for the calculation of low-level climatological wind fields using a mesoscale boundary-layer model. In press Bound.-Layer Meteor.

Black T.L. (1994). The new NMC mesoscale Eta model: Description and forecast examples, Wea. Forecasting, 9, 265-278pp.

Bustamante, J.; Gomes, J. L.; Chou, S.C.; \& Rozante, J. R. (1999). Evaluation of April 1999 rainfall forecasts over South America using the Eta Model. Climanálise, No 5, Cachoeira Paulista, SP, Brazil.

Case J.L., Manobianco J., Lane J.E., Immer C.D., \& Merceret F.J. (2004). An Objective Technique for Verifying Sea Breezes in High-Resolution Numerical Weather Prediction Models, Wea. Forecasting , 19, 690-705pp.

Colby F.P. Jr. (2004). Simulation of the New England Sea Breeze: The effect of Grid Spacing, Wea. Forecasting, 19, 277-285pp.

Cormier D.R. \& Marsh L. (2001). Spline Regression Models. Sage Publications, Thousand Oaks, California, 80 pp.

Cressman G.P. (1959). An operative objective analysis scheme. Mon. Wea. Rev., 87, 367374pp.

Daggupaty S.M. (2001). A Case Study of the simultaneous Development of Multiple Lake-Breeze Fronts with a Boundary Layer Forecast Model, J. Appl. Meteorol., 40, 289-311pp.

Hanna S. R. \& Yang R. (2001). Evaluations of mesoscale models' simulations of near-surface winds, temperature gradients, and mixing depths, J. Appl. Meteorol., 40, 1095$1104 \mathrm{pp}$.

Mesinger F. \& Black T.L. (1992). On the impact on forecast accuracy of the step-mountain (eta) vs. sigma coordinate, Meteorol. Atmos. Phys., 50, 47-60pp.

Pielke R.A. (1974). A Three Dimensional Numerical Model of the Sea Breezes Over the South Florida, Mon. Wea. Rev. 102, 115-139pp.

Pielke R.A., Cotton W.R., Walko R.L., Tremback C.J., Lyons W.A., Grasso L.D., Nicholls M.E., Moran M.D., Wesley D.A., Lee T.J. \& Copeland J.H. (1992). A Comprehensive Meteorological Modeling System RAMS, Meteorol. Atmos. Phys., 49, 69-91pp.

Roebber P.J. \& Gehring Mark G. (2000). Real-Time Prediction of the Lake Breeze on the Western Shore of Lake Michigan, Wea. Forecasting, 15, 298-312.

Seluchi M.E. \& Chou S.C. (2001). Evaluation of two Eta model versions over South America, Rev. Geofis., 40, 219-238.

Sraibman L., \& G.J. Berri, (2009). Low level wind forecast over La Plata River region with a mesoscale boundary layer model forced by regional operational forecasts, Boundary Layer Meteorology, 130, 407-422.

White B.G., Paegle J., Steenburgh J.W., Horel J.D., Swanson R.T., Cook L.K, Onton D.J. \& Miles J.G. (1999). Short-term forecast validation of six models, Wea. Forecasting, 14, 84-108.

Wilks, Daniel S. (1995). Statistical Methods in the Atmospheric Sciences, Academic Press, 240 pp. 
Zhang Y., Chen Y., Schroeder T.H. \& Kodama K. (2005). Numerical Simulations of SeaBreeze Circulations over Northwest Hawaii, Wea. Forecasting, 20, 827-846.

Zhong S. \& Fast J. (2003). An Evaluation of the MM5, RAMS, and Meso-Eta Models at Subkilometer Resolution Using VTMX Field Campaign Data in the Salt Lake Valley, Mon. Wea. Rev, 131, 1301-1322. 


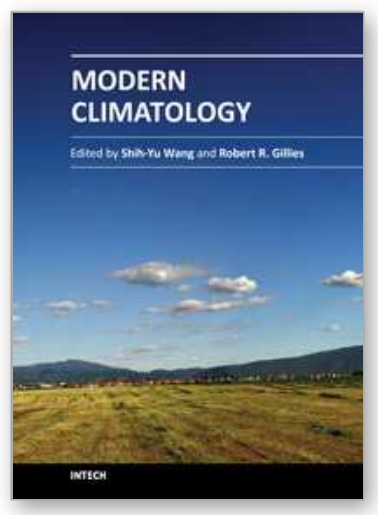

\author{
Modern Climatology \\ Edited by Dr Shih-Yu Wang
}

ISBN 978-953-51-0095-9

Hard cover, 398 pages

Publisher InTech

Published online 09, March, 2012

Published in print edition March, 2012

Climatology, the study of climate, is no longer regarded as a single discipline that treats climate as something that fluctuates only within the unchanging boundaries described by historical statistics. The field has recognized that climate is something that changes continually under the influence of physical and biological forces and so, cannot be understood in isolation but rather, is one that includes diverse scientific disciplines that play their role in understanding a highly complex coupled "whole system" that is the earth's climate. The modern era of climatology is echoed in this book. On the one hand it offers a broad synoptic perspective but also considers the regional standpoint, as it is this that affects what people need from climatology. Aspects on the topic of climate change - what is often considered a contradiction in terms - is also addressed. It is all too evident these days that what recent work in climatology has revealed carries profound implications for economic and social policy; it is with these in mind that the final chapters consider acumens as to the application of what has been learned to date.

\title{
How to reference
}

In order to correctly reference this scholarly work, feel free to copy and paste the following:

Guillermo J. Berri (2012). Synthesizing High-Resolution Climatological Wind Fields with a Mesoscale Atmospheric Boundary Layer Model Forced with Local Weather Observations, Modern Climatology, Dr ShihYu Wang (Ed.), ISBN: 978-953-51-0095-9, InTech, Available from: http://www.intechopen.com/books/modernclimatology/synthesizing-high-resolution-climatological-wind-fields-with-a-mesoscale-atmospheric-boundarylayer-

\section{INTECH}

open science | open minds

\section{InTech Europe}

University Campus STeP Ri

Slavka Krautzeka 83/A

51000 Rijeka, Croatia

Phone: +385 (51) 770447

Fax: +385 (51) 686166

www.intechopen.com

\section{InTech China}

Unit 405, Office Block, Hotel Equatorial Shanghai

No.65, Yan An Road (West), Shanghai, 200040, China 中国上海市延安西路65号上海国际贵都大饭店办公楼 405 单元

Phone: +86-21-62489820

Fax: $+86-21-62489821$ 
(C) 2012 The Author(s). Licensee IntechOpen. This is an open access article distributed under the terms of the Creative Commons Attribution 3.0 License, which permits unrestricted use, distribution, and reproduction in any medium, provided the original work is properly cited. 